\title{
¿Impact of Reduced Arctic Sea Ice on Northern Hemisphere Climate and Weather in Autumn and Winter()
}

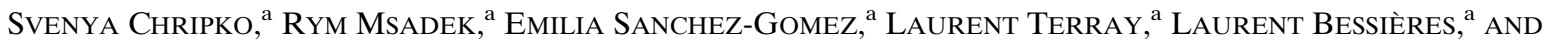 \\ MARIE-PIERRE MOINE ${ }^{\mathrm{a}}$ \\ ${ }^{\mathrm{a}}$ CECI, Université de Toulouse, CNRS, CERFACS, Toulouse, France
}

(Manuscript received 6 July 2020, in final form 13 April 2021)

\begin{abstract}
The Northern Hemisphere transient atmospheric response to Arctic sea decline is investigated in autumn and winter, using sensitivity experiments performed with the CNRM-CM6-1 high-top climate model. Arctic sea ice albedo is reduced to the ocean value, yielding ice-free conditions during summer and a more moderate sea ice reduction during the following months. A strong amplification of temperatures over the Arctic is induced by sea ice loss, with values reaching up to $25^{\circ} \mathrm{C}$ near the surface in autumn. Significant surface temperature anomalies are also found over the midlatitudes, with a warming reaching $1^{\circ} \mathrm{C}$ over North America and Europe, and a cooling reaching $1^{\circ} \mathrm{C}$ over central Asia. Using a dynamical adjustment method based on a regional reconstruction of circulation analogs, we show that the warming over North America and Europe can be explained both by changes in the atmospheric circulation and by the advection of warmer oceanic air by the climatological flow. In contrast, we demonstrate that the sea ice-induced cooling over central Asia is solely due to dynamical changes, involving an intensification of the Siberian high and a cyclonic anomaly over the Sea of Okhotsk. In the troposphere, the abrupt Arctic sea ice decline favors a narrowing of the subtropical jet stream and a slight weakening of the lower part of the polar vortex that is explained by a weak enhancement of upward wave activity toward the stratosphere. We further show that reduced Arctic sea ice in our experiments is mainly associated with less severe cold extremes in the midlatitudes.
\end{abstract}

KEYWORDS: Arctic; Sea ice; Atmospheric circulation; Teleconnections; Annular mode; Arctic Oscillation; Stratospheretroposphere coupling; Climate models

\section{Introduction}

Over the last three decades, surface temperatures in the Arctic region have been increasing twice as fast as global mean temperature (Bindoff et al. 2013). This phenomenon is called Arctic amplification and is strongest in winter (Bintanja and van der Linden 2013). One major consequence of this effect is the decline of Arctic sea ice that has been observed since the beginning of satellite measurements (Serreze et al. 2009; Screen and Simmonds 2010a). Arctic sea ice extent has decreased in every month and every season (Onarheim et al. 2018), and particularly in summer with a rate of more than $10 \%$ per decade since 1979 (Stroeve et al. 2012). Furthermore, future climate projections indicate a high probability of having ice-free summers by the middle to end of the twenty-first century in response to the increasing greenhouse gas concentrations (Notz et al. 2020). Sea ice decline also tends to reinforce Arctic amplification, mainly through infrared radiation feedbacks and through the delayed positive surface albedo feedback (Bintanja and van der Linden 2013). The latter

๖ Denotes content that is immediately available upon publication as open access.

Supplemental information related to this paper is available at the Journals Online website: https://doi.org/10.1175/JCLI-D-200515.s1.

Corresponding author: Svenya Chripko, chripko@cerfacs.fr contributes to the amplification of the warming in the lower troposphere in autumn and winter, when the transfer of energy between the ocean and the atmosphere is the strongest (Screen and Simmonds 2010b).

Arctic sea ice loss affects local weather through the increased amount of energy and moisture released in the atmosphere when sea ice has melted, leading to warmer and wetter Arctic air masses (Vihma 2014). It was also suggested that Arctic sea ice loss could affect lower latitudes through southward advection of the warmer Arctic air masses-the direct contribution-and possibly through changes of the large-scale atmospheric circulation - the indirect contribution (Screen et al. 2018). However, these two contributions could oppose each other (Screen 2017) and the mechanisms leading to a change in atmospheric circulation are still not fully understood. In observational studies, a positive correlation was found between Arctic sea ice decline and cold winters over Eurasia and North America since the 1980s - the warm Arctic and cold continents (WACC) pattern (Overland et al. 2011; Cohen et al. 2013), sometimes restricted to the warm Arctic and cold Eurasia (WACE) pattern (Mori et al. 2014, 2019). Observations also suggest a link between Arctic sea ice decline and the negative phase of the northern annular mode (NAM), also called the Arctic Oscillation (AO), which is the dominant mode of wintertime Northern Hemisphere atmospheric variability (Jaiser et al. 2012; Cohen et al. 2012;

This article is licensed under a Creative Commons Attribution 4.0 license (http://creativecommons.org/ licenses/by/4.0/).

DOI: 10.1175/JCLI-D-20-0515.1 
Nakamura et al. 2015). This raises the question of the role of Arctic sea ice decline in modulating Northern Hemisphere climate variability and affecting midlatitude weather and climate. However, statistical correlations do not necessarily imply a causal link (Smith et al. 2017; Screen et al. 2018), and analysis based on observations can have some limitations due to the limited length of the observational records and the nonstationarity of the relationship between sea ice and the midlatitude weather and climate (Blackport and Screen 2020). Modeling studies can provide useful insights as they allow us to isolate the impacts of Arctic sea ice loss from those driven by greenhouse gas increase.

Many climate model studies have been dedicated to the understanding of the influence of past or projected Arctic sea ice loss on lower latitudes. However, the detection of a robust atmospheric response to Arctic sea ice loss is difficult due to several key differences across the modeling experiments: the magnitude and spatial pattern of the prescribed sea ice loss, the background mean state, the representation or lack of oceanatmosphere and troposphere-stratosphere coupling, the transient versus equilibrium response, or model biases (Smith et al. 2017; Screen et al. 2018). In addition, large ensembles of simulations are needed to isolate the forced response from internal atmospheric variability, suggesting that the effect of Arctic sea ice loss on the atmospheric circulation is probably small (Screen 2014). Several modeling experiments have suggested that the anomalously cold winters observed in the midlatitudes could be the result of internal variability rather than being driven by Arctic sea ice reduction (Screen et al. 2013; Blackport and Kushner 2016; Chen et al. 2016; Sun et al. 2016; McCusker et al. 2016; Ogawa et al. 2018; Dai and Song 2020). This is in agreement with the observational study of Blackport et al. (2019), which suggested that the anomalously cold observed midlatitude winters could be driven by atmospheric circulation anomalies that precede sea ice loss rather than by the sea ice anomaly itself. However, this does not preclude a possible influence of Arctic sea ice loss in the future, as suggested by idealized experiments that show that projected late-twenty-first-century sea ice reduction could lead to significant weather and climate anomalies in the Northern Hemisphere (e.g., Sun et al. 2018).

The atmospheric response to Arctic sea ice reduction shows some similarities with the negative phase of the NAM in some atmosphere-only experiments (Deser et al. 2010; Peings and Magnusdottir 2014; Sun et al. 2015). Others find however an opposite response (Screen et al. 2014; Cassano et al. 2014). More robustness is found in coupled ocean-atmosphere model experiments in which the imposed sea ice forcing is often larger (Screen et al. 2018). These models show that Arctic sea ice loss favors a decrease and equatorward shift of the midlatitude westerly winds accompanied with a strengthening of the subtropical jet stream, an intensification of the Siberian high and Aleutian low, and a weakening of the Icelandic low. Oceanatmosphere coupling may also favor a stronger response than in atmosphere-only experiments for equal magnitudes of sea ice perturbation (e.g., Peings et al. 2021). Moreover, several modeling studies have shown that the atmospheric response to Arctic sea ice loss can extend southward to the tropics with active ocean-atmosphere coupling (Deser et al. 2015; Wang et al. 2018; England et al. 2020).
The hypothesized processes through which Arctic amplification could influence the midlatitude circulation involve either tropospheric or tropospheric-stratospheric pathways (Barnes and Screen 2015). Recent studies have highlighted the role of troposphere-stratosphere interactions in the time and spatial evolution of the large-scale atmospheric response to sea ice decline. They showed that planetary-scale waves might propagate from the troposphere to the lower stratosphere in response to sea ice loss in early winter (Cohen et al. 2014), with a reinforced propagation when there is a linear interference between the forced waves and the climatological waves (Garfinkel et al. 2010; Smith and Kushner 2012). If the planetary waves reach the lower stratosphere and break, the polar vortex is weakened (Charney and Drazin 1961; Limpasuvan et al. 2004). In turn, this stratospheric anomaly can propagate downward and further weaken the tropospheric jet stream, forcing the negative phase of the NAM (Jaiser et al. 2013). The characteristics of the stratospheric response and associated mechanisms vary among studies. Some modeling studies show a weakening of the polar vortex as a result of sea ice loss (Peings and Magnusdottir 2014; Kim et al. 2014), while others find a strengthening (Screen et al. 2013; Sun et al. 2014) or no amplification of planetary waves (Meleshko et al. 2016). Peings and Magnusdottir (2014) found that imposed sea ice anomalies from the period 2007-12 yield an increase in planetary wave activity and a weakening of the stratospheric polar vortex, preceding the negative phase of the NAM. They investigated the linearity of the response by imposing a stronger sea ice forcing corresponding to conditions expected at the end of the century. They found a stronger NAM-like tropospheric response and a much weaker stratospheric response, suggesting that the response in the stratosphere is nonlinear with respect to the magnitude of sea ice loss. Furthermore, other modeling experiments have suggested that sea ice loss in the Atlantic and in the Pacific sectors could drive opposite changes in the stratosphere, with respectively a weakening and a strengthening of the polar vortex (Sun et al. 2015; McKenna et al. 2018). McKenna et al. (2018) also found that a similar NAM response is induced in the troposphere for both sectors when a large magnitude of sea ice loss is applied, suggesting that a larger magnitude of sea ice loss could increase the preponderance of tropospheric processes with respect to stratospheric processes. Specific experiments that have isolated the tropospheric and stratospheric pathways using stratospheric nudging indicate that the stratosphere could play an important role for the development of the atmospheric response to sea ice decline (Wu and Smith 2016; Nakamura et al. 2016; Zhang et al. 2018).

One motivation for better understanding the atmospheric response to Arctic sea ice decline is the possible link with midlatitude weather extremes. This has received a lot of attention among observational and modeling studies, but no consensus has emerged yet (Cohen et al. 2020). A reduction in the meridional temperature gradient due to Arctic lower tropospheric warming may reduce baroclinicity and shift storm tracks equatorward (Magnusdottir et al. 2004; Oudar et al. 2017). Arctic amplification may also lead to more persistent midlatitude weather patterns and hence more extreme weather events due to a slower eastward propagation of planetary-scale waves (Francis and Vavrus 2012). The proposed mechanism 
includes first a reduction in the meridional temperature gradient that would slow down the jet stream according to the thermal wind balance and then slow down the horizontal propagation of waves, favoring prolonged weather conditions. Another link would result from an increased meridional amplitude of planetary-waves that would increase the waviness of the jet stream and favor the intrusion of cold air southward and warm air northward. This would also slow down the eastward propagation of waves, yielding more persistent and extreme weather. However, these links remain controversial as the results have been shown to strongly depend on the methodology used to define relevant time scales for the analysis of planetary waves, either daily or seasonal (Barnes 2013). Colder extreme temperatures over Eurasia and/or North America have been reported in some studies in response to Arctic sea ice decline (Zhang et al. 2018). Their intensity has been shown to increase nonlinearly with respect to the magnitude of sea ice loss (Peings and Magnusdottir 2014). However, less frequent cold extremes over North America were also obtained as a result of Arctic sea ice loss (Screen et al. 2015). Screen (2014) showed that Arctic amplification as observed during the past decades and in future climate could decrease both temperature variability and the number of temperature extremes in the midlatitudes. Despite the link described in some studies between Arctic sea ice loss and extreme temperature changes over land, no robust change in waviness has been found (Peings and Magnusdottir 2014; Oudar et al. 2017; Blackport and Screen 2020), suggesting the need to better investigate this link both in observations and in models.

In this study, we investigate the transient wintertime atmospheric response to Arctic sea ice loss in the Northern Hemisphere using the high-top coupled climate model CNRMCM6-1. Idealized experiments with ice-free summertime conditions and more moderate wintertime sea ice reduction are performed. We are interested in the atmospheric response that follows sea ice reduction by few months. Hence, only the ocean-atmosphere feedbacks that occur on these short time scales are accounted for. We do not consider the longer time scale oceanic changes like those associated with thermohaline or gyre modifications. With the strong imposed forcing and the great ensemble member size, the high-top configuration allows us to account for stratospheric processes that have been shown to play a role on the response. The goal of this study is to characterize the month-to-month changes in atmospheric circulation that can occur in response to abrupt Arctic sea ice reduction and to determine associated impacts in terms of surface air temperature. First, we focus on the physical mechanisms underlying the surface temperature response through a decomposition into a dynamically induced component and a residual component. Second, we investigate the interaction mechanisms between the troposphere and stratosphere in the circulation response. Finally, we analyze the effects of Arctic sea ice decline on cold extreme temperatures.

In section 2 we present the model, sensitivity experiments, and methods used to analyze the atmospheric response to Arctic sea ice loss. In section 3 we describe the response and the possible mechanisms at play. In section 4 we summarize the main points and discuss the results.

\section{Sensitivity experiments and methods}

\section{a. Model description}

We use CNRM-CM6-1, the fully coupled atmosphere-ocean general circulation model recently developed by the CNRM/ CERFACS modeling group for CMIP6 (Voldoire et al. 2019). The atmospheric component of CNRM-CM6-1 is the high-top ARPEGE-Climat version 6.3, with a horizontal resolution of $1.4^{\circ}$ at the equator on a reduced Gaussian grid (linear triangular truncation T1127). It is discretized into 91 vertical levels extending up to $0.01 \mathrm{hPa}$, resolving the stratosphere and the mesosphere. The model has a relatively well-represented quasi-biennial oscillation (QBO), and it is able to simulate the Holton-Tan effect, which links the QBO to the winter stratospheric polar vortex (Rao et al. 2020). The surface component is SURFEX version 8, which simulates the surface fluxes over land, lakes, and oceans. It is embedded within ARPEGE-Climat and therefore shares the same horizontal grid. The ocean component is NEMO version 3.6 (Madec et al. 2017) with a nominal resolution of $1^{\circ}$ (eORCA1 horizontal tripolar grid) and 75 vertical levels. The sea ice component, embedded within NEMO, is GELATO version 6, which has five ice thickness categories and nine vertical layers. ARPEGE-SURFEX and NEMO-GELATO are coupled using the OASIS3-MCT software (Craig et al. 2017). A complete description of the characteristics of CNRM-CM6-1 is provided by Voldoire et al. (2019).

\section{b. Sea ice perturbation}

To investigate the role of Arctic sea ice loss on the atmosphere, we perform two sets of simulations with CNRM-CM6-1: a control experiment and perturbed experiments. The control experiment is a 150 -yr simulation with prescribed constant external forcings fixed to climate conditions of 1950 after a spinup of 30 years (Haarsma et al. 2016). The spinup starts from an ocean at rest with temperature and salinity taken from the EN4 dataset (Good et al. 2013). This spinup is short for the deep ocean adjustment to take place, but given that the focus of this study is on the atmospheric response, we do not expect a strong negative impact resulting from this protocol. The perturbed experiments consist of 100 members initialized randomly every one or two years from the control experiment, in which sea ice albedo is reduced to the ocean value (0.07). Each member is run for 3 years. We checked that on average the members are not initialized with a particular phase of the QBO from the control experiment, which could have favored teleconnections between the tropical and polar stratosphere and could have affected the polar vortex response to Arctic sea ice loss (Labe et al. 2019).

Figure 1 shows the seasonal cycles of Arctic sea extent and volume in the 100-member perturbed experiments and the 100member overlapping control periods. Only the first 30 months are shown. We find a complete melt of Arctic sea ice both in terms of extent and volume during all summer months from July to October. This can be explained by the increased incoming solar radiation resulting from the modified albedo. Every summer it corresponds to a loss of sea ice extent of $(10 \pm$ 2) $\times 10^{6} \mathrm{~km}^{2}$ and a loss of sea ice volume of $(7 \pm 2) \times 10^{3} \mathrm{~km}^{2}$. Note that while the experiments are started in January, in the 
(a) Sea Ice Extent

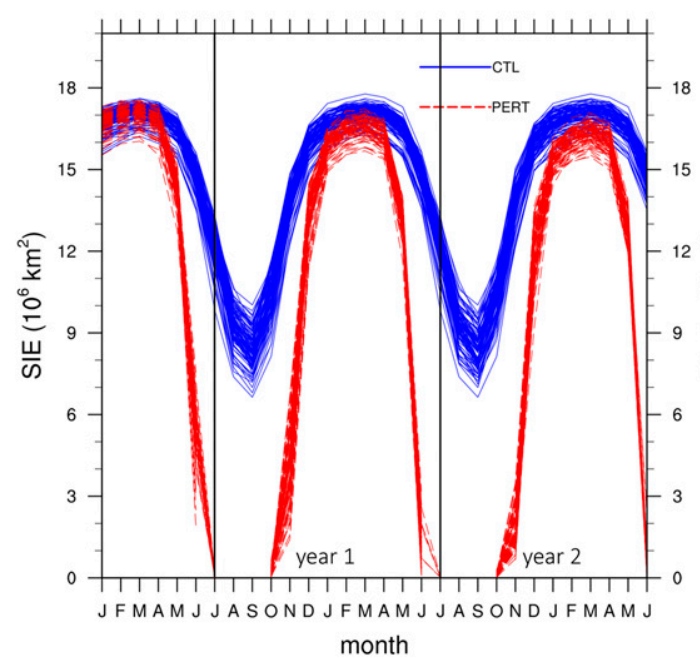

(b) Sea Ice Volume

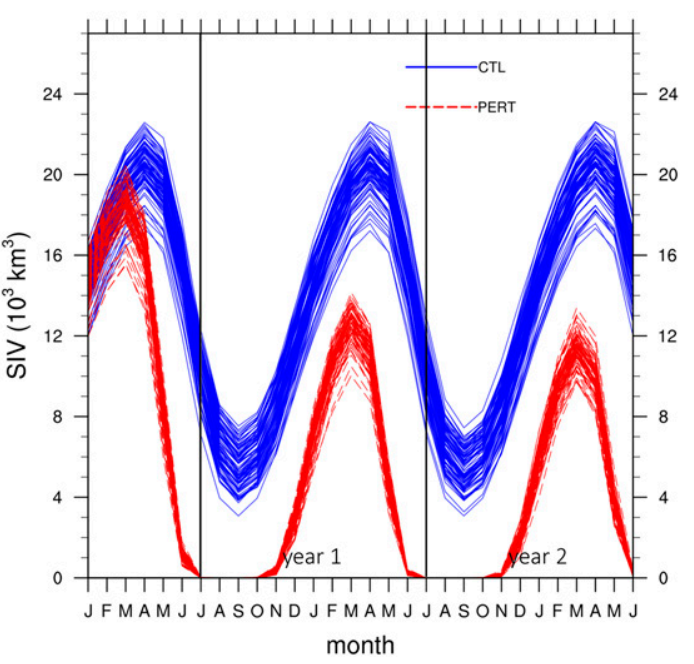

FIG. 1. Seasonal cycles of Arctic (a) sea ice extent (SIE; $10^{6} \mathrm{~km}^{2}$ ) and (b) sea ice volume (SIV; $10^{3} \mathrm{~km}^{3}$ ) for the 100 perturbed runs (red) and the respective control states (blue) during the 30 first months of the simulations.

following we will not use the first 6 months (January-June) as we are interested in the autumn and wintertime atmospheric response that follows a complete summertime sea ice loss. This rapid atmospheric response is expected to occur in phase with sea ice loss during autumn and winter (Blackport and Screen 2019), but the possible link between autumn and winter responses will be discussed in this study. During the two winter seasons (January-March), reduction in sea ice extent is not as marked as in the previous summer season with a loss of $(0.6 \pm$ $0.4) \times 10^{6} \mathrm{~km}^{2}$ (4\% of the control mean) the first winter and $(0.9 \pm 0.5) \times 10^{6} \mathrm{~km}^{2}(5 \%)$ the second winter (Fig. 1). Sea ice is moreover much younger and hence thinner after the very large volume loss perturbation of $(7 \pm 2) \times 10^{3} \mathrm{~km}^{3}(40 \%)$ that occurs during the first winter and $(8 \pm 2) \times 10^{3} \mathrm{~km}^{3}$ $(48 \%)$ the second one. Note that sea ice reduction in our experiments is very large and unrealistic. Wintertime sea ice loss is still larger by one order of magnitude than the year-toyear 1979-2019 observed trend, which is about $0.041 \times$ $10^{6} \mathrm{~km}^{2}$ for March sea ice extent (Meredith et al. 2019) and about $0.27 \times 10^{3} \mathrm{~km}^{3}$ for April SIV (PIOMAS; Schweiger et al. 2011). In view of these small differences between the two years, we consider that they are statistically independent and therefore analyze an ensemble of 200 wintertime periods ( 2 years $\times 100$ members). We justify our choice by the lack of statistically significant difference in the atmospheric response between the two years (see supplement SM1 in the online supplemental material). Note that the sea ice albedo changes are applied globally, but as we focus only on the rapid response during the first two years we can discard any influence of Antarctic sea ice changes on these time scales. The same protocol and assumptions were used by Blackport and Kushner (2016). The ensemble mean of the perturbed experiment is hereinafter called PERT. In the same way, CTL refers to the ensemble mean of the control periods overlapping the perturbed simulations. The climate response to the imposed sea ice loss is computed by subtracting CTL from PERT for several atmospheric variables.

To visualize the spatial distribution of sea ice loss, we show in Fig. 2 the sea ice response in terms of sea ice concentration (SIC) and sea ice volume (SIV) averaged over the 200 members, starting in July and for different seasons. We define the summer season as the July-September average (JAS), the autumn season as the October-December average (OND), the winter season as the January-March average (JFM) and the spring season as the April-June average (AMJ). In summer, most of sea ice concentration is lost over central Arctic where the sea ice layer is the thickest. In autumn, the reduction is largest over the Chukchi and Barents Seas with a net loss of about 85 percentage points in concentration (PERT SIC CTL SIC). Sea ice loss is also large over central Arctic and the Canadian Bays with more than 60 percentage points of sea ice concentration being lost. In winter, sea ice loss occurs mainly at the climatological edges in the Barents Sea, Greenland, Iceland, and Norwegian Seas, and the Labrador, Bering, and Okhotsk Seas where it can reach a decline of up to 40 percentage points. In spring, sea ice concentration loss is found over the whole Arctic with values reaching about 40 percentage points. Note that the reduction of sea ice volume is strongest over central Arctic for all seasons and is largest in spring.

\section{c. Methods}

\section{1) DYNAMICAL ADJUSTMENT}

To extract the role of atmospheric circulation changes in the near-surface atmospheric temperature (SAT) response, we use the dynamical adjustment approach described in Deser et al. (2016b) and also used by O'Reilly et al. (2017). The method is based on a circulation analog reconstruction that allows to identify the dynamical SAT response solely due to circulation changes occurring in response to sea ice loss. For each PERT 

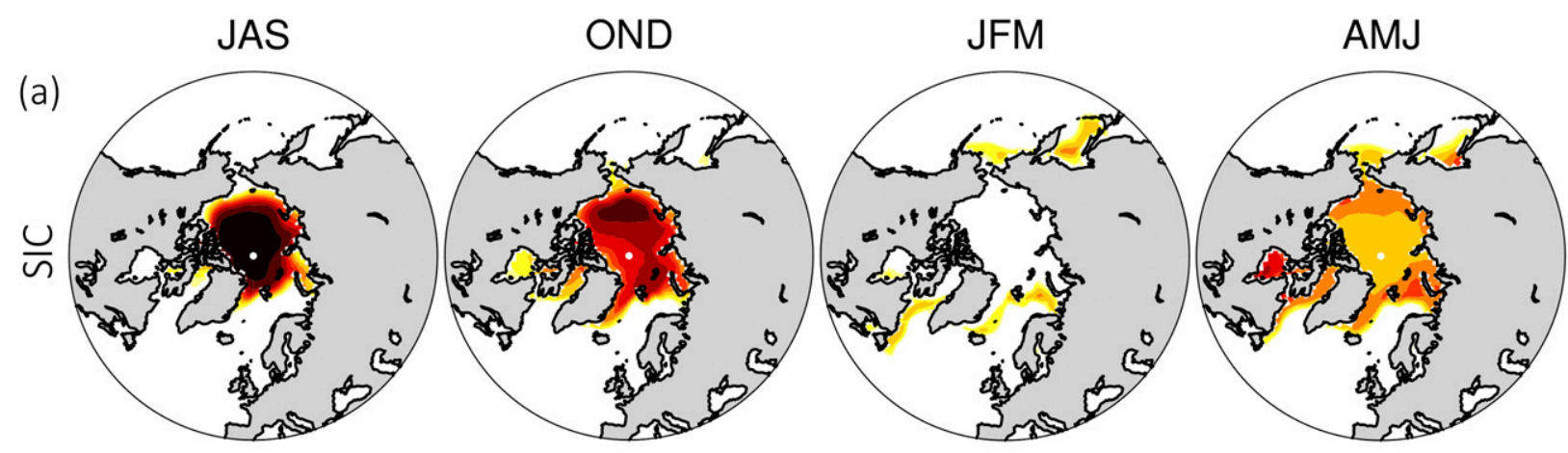

(\%)

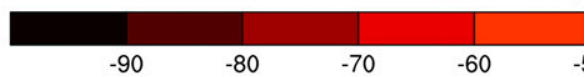

$-50$

(b)
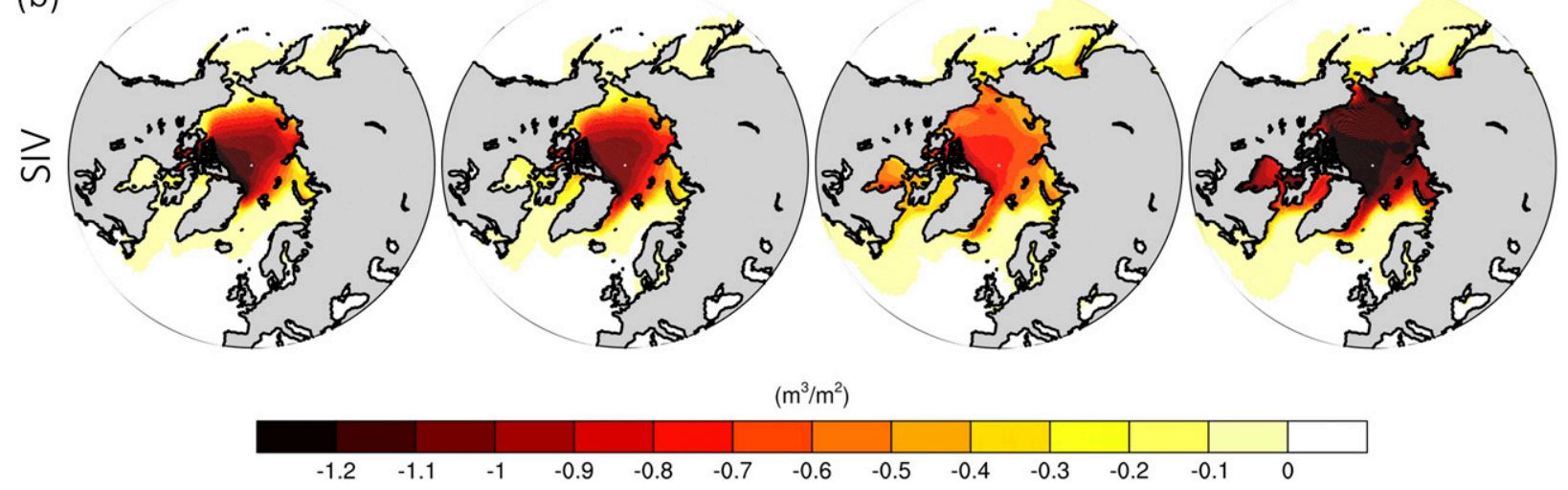

FIG. 2. Spatial distribution of (a) sea ice concentration (SIC) response (\%) and (b) sea ice volume (SIV) response $\left(\mathrm{m}^{3} \mathrm{~m}^{-2}\right)$ in summer

[July-September (JAS)], autumn [October-December (OND)], winter [January-March (JFM)], and spring [April-June (AMJ)].

member and month, the closest sea level pressure (SLP) analogs in CTL are selected by minimizing the Teweles-Wobus score (Teweles and Wobus 1954). The PERT monthly mean SLP is then reconstructed from a set of SLP patterns (selected randomly among the closest SLP analogs from CTL) using multiple linear regression. The regression coefficients are subsequently applied to the corresponding monthly mean SAT in CTL to provide an estimate of SAT associated with circulation changes. These steps are repeated 200 times and the final dynamical SAT estimate for this PERT simulation and month is the average of the individual SAT estimates over the 200 iterations. After averaging this value over the 200 members and subtracting the CTL temperature from it, we obtain the dynamical contribution of the SAT response for a given month. The dynamical SAT represents the so-called mean contribution of the SAT changes due to atmospheric circulation, including both advective and local effects. Here, the use of "mean" can be viewed as a climatological average over multiple land and ocean surface conditions. The residual SAT response is then obtained by subtracting the dynamical response from the total response. Note that this residual response mainly corresponds to a thermodynamic contribution. It can include several processes like advection of anomalous oceanic air masses by the climatological flow but also local effects due to changes in the surface energy budget over land surface (e.g., snow cover, soil moisture, or cloud cover changes). The residual part can also include errors due to the analog reconstruction, but these are found to be small (not shown).

We compute the decomposition of the SAT response into dynamical and residual components on three midlatitude regions that are shown in Fig. 7: North America (defined as $30^{\circ}-$ $\left.60^{\circ} \mathrm{N}, 140^{\circ}-50^{\circ} \mathrm{W}\right)$, Europe $\left(35^{\circ}-60^{\circ} \mathrm{N}, 15^{\circ} \mathrm{W}-45^{\circ} \mathrm{E}\right)$, and central Asia $\left(30^{\circ}-50^{\circ} \mathrm{N}, 70^{\circ}-125^{\circ} \mathrm{E}\right)$. To do that, we apply the dynamical adjustment method on each of the three target regions. Note that the method is insensitive to variations in the longitudinal size of the region (i.e., smaller than $\pm 30^{\circ}$ in both directions), but it provides a better reconstruction of the circulation analogs than a global approach (root-meansquare error improved by a factor of 10; not shown).

\section{2) Planetary WAVE-MEAN Flow INTERACTION}

To analyze the interaction between the circulation changes in the troposphere and the stratosphere, we use the EliassenPalm (EP) flux formulation defined by Edmon et al. (1980). For planetary-scale eddy dynamics, the EP flux vector $\mathbf{F}$ represents the transfer of wave activity according to the latitude and pressure level; in other words it represents the direction of wave propagation. The horizontal component of the EP flux 
vector is proportional to the negative of the northward eddy angular momentum flux and the vertical component is proportional to the northward eddy heat flux. The EP flux divergence represents the magnitude of the eddy forcing on the zonal mean flow. The latter accelerates where the EP flux diverges and decelerates where the EP flux converges (Holton 1992). We compute the response of the EP flux vectors and divergence using daily data that are first low-pass filtered to keep planetary-scale fluctuations with periods larger than 10 days. We perform a scaling of $\mathbf{F}$ by applying the convention described in Edmon et al. (1980): the vertical component is multiplied by the cosine of latitude and by the distance occupied by $1 \mathrm{~Pa}$ on the diagram. The horizontal component is divided by the radius of Earth and multiplied by the distance occupied by $1 \mathrm{rad}$ of latitude. Both components are scaled by $\sqrt{1000 / p}$, with $p$ being the pressure $(\mathrm{hPa})$. They are also scaled by a magnification factor of 3 above $100 \mathrm{hPa}$ to extend the vectors in the stratosphere (e.g., Sun et al. 2015).

\section{3) StATisticAl SIGNIFICANCE}

To evaluate the statistical significance of the atmospheric response, we first use a two-sided Student's $t$ test to compute the $p$ values. We then account for field significance by using the false discovery rate (FDR; Wilks 2016) with $\alpha_{\mathrm{FDR}}=0.05$. The FDR correction computes a threshold level based on the sorted distribution of the Student's $t$ test $p$ values. This yields a global achieved test level of 0.025 (97.5\% confidence level) for the variables with moderate and relatively strong spatial autocorrelation described in this study, such as near-surface air temperature or zonal-mean zonal winds, and a global achieved test level of 0.05 ( $95 \%$ confidence level) for the variables with low spatial correlation (Wilks 2016), such as sea level pressure. Figure S2 in the online supplemental material highlights the importance of taking into account the FDR to address properly the statistical significance of the atmospheric response.

\section{Atmospheric response to Arctic sea ice loss}

\section{a. Surface energy budget response over the Arctic Ocean}

The changes in Arctic sea ice cover and thickness that occur in response to the modified sea ice albedo affect the local surface energy budget. Figure 3 illustrates the monthly response of the net surface energy fluxes and details the respective contributions of turbulent fluxes (sensible and latent), as well as longwave and shortwave radiative fluxes. The seasonal cycle of the SIC loss is also shown for comparison as a histogram. A positive flux corresponds to an energy flux from the ocean to the atmosphere, therefore adding heat to lowest atmospheric levels. The net surface energy flux response follows a marked seasonal cycle, with a maximum in November and a minimum in May/June. The negative fluxes during the summer/spring months indicate an increased absorption of shortwave radiation by the ice-free Arctic Ocean caused by the sea ice albedo perturbation. The positive fluxes during the autumn/winter months correspond to an increased absorption of longwave radiation by the atmosphere and to a larger oceanic heat loss in the form of turbulent heat fluxes. This larger wintertime exchange of energy from the ocean to the

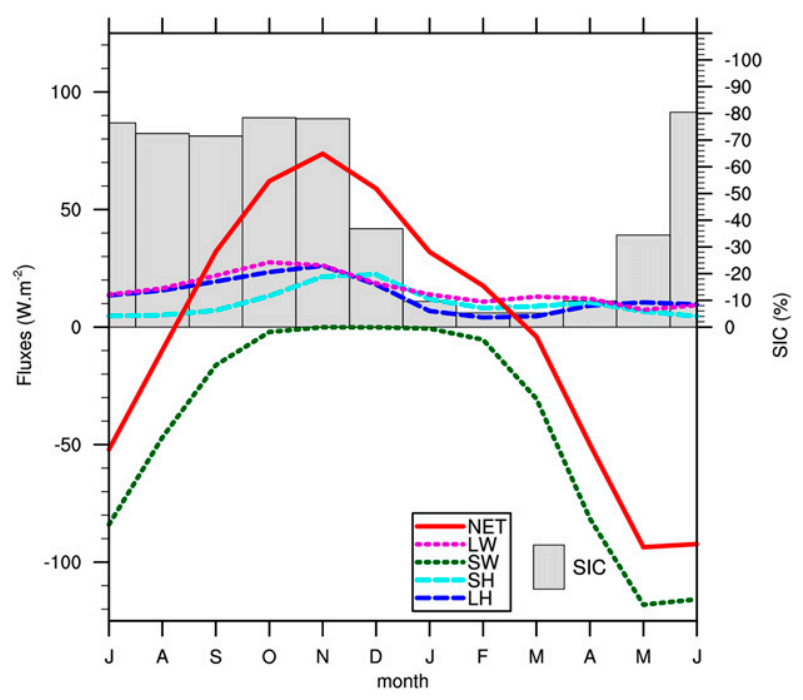

FIG. 3. Seasonal cycle of the response of the net surface energy absorbed by the atmosphere (red curve), the longwave (magenta curve) and shortwave (green curve) radiative fluxes, and the sensible (cyan curve) and latent (blue curve) heat fluxes (scale for fluxes on the left; $\mathrm{W} \mathrm{m}^{-2}$ ). Positive fluxes are upward. Seasonal cycle of the SIC response (gray bars; scale on the right: \%). The responses are averaged month by month over the Arctic sea ice covered regions where SIC exceeds $15 \%$ in the control run north of $60^{\circ} \mathrm{N}$.

atmosphere is explained by warmer local sea surface temperatures (SSTs) starting from the previous summer months as a result of sea ice loss. Moreover, Fig. 3 shows that there is a maximum of energy absorbed by the atmosphere in November, nearly in phase with the maximum of SIC loss occurring in October-November. From this surface energy budget analysis, we expect that the strongest atmospheric response to sea ice loss in our experiments will occur in November. Hence, in the following sections, we will focus on the atmospheric response to Arctic sea ice reduction from November through February, when the strongest Arctic amplification and remote response occur. Given that seasonal averages can mask processes that occur rapidly from one month to the other, in particular in the stratosphere (see supplement SM2 in the online supplemental material), we will use monthly averages.

\section{b. Monthly evolution of the atmospheric response}

\section{1) ZONAL-MEAN RESPONSE IN THE TROPOSPHERE AND STRATOSPHERE}

The perturbed Arctic surface energy budget due to the imposed sea ice melt not only modifies local air masses, but also leads to changes in atmospheric circulation up to the stratosphere and the tropics. The zonal-mean response of temperature, geopotential height, and zonal wind are represented in Fig. 4.

As a result of sea ice loss, Arctic amplification extends up to midtropospheric levels around $500 \mathrm{hPa}$ for each month (Fig. 4a). The strongest magnitude is found in November, in phase with the maximum net surface energy budget response obtained in Fig. 3, and it reaches up to $20^{\circ} \mathrm{C}$ in the near surface. In the polar stratosphere, a significant cooling is found in November at the tropopause and at the polar vortex core. During the 

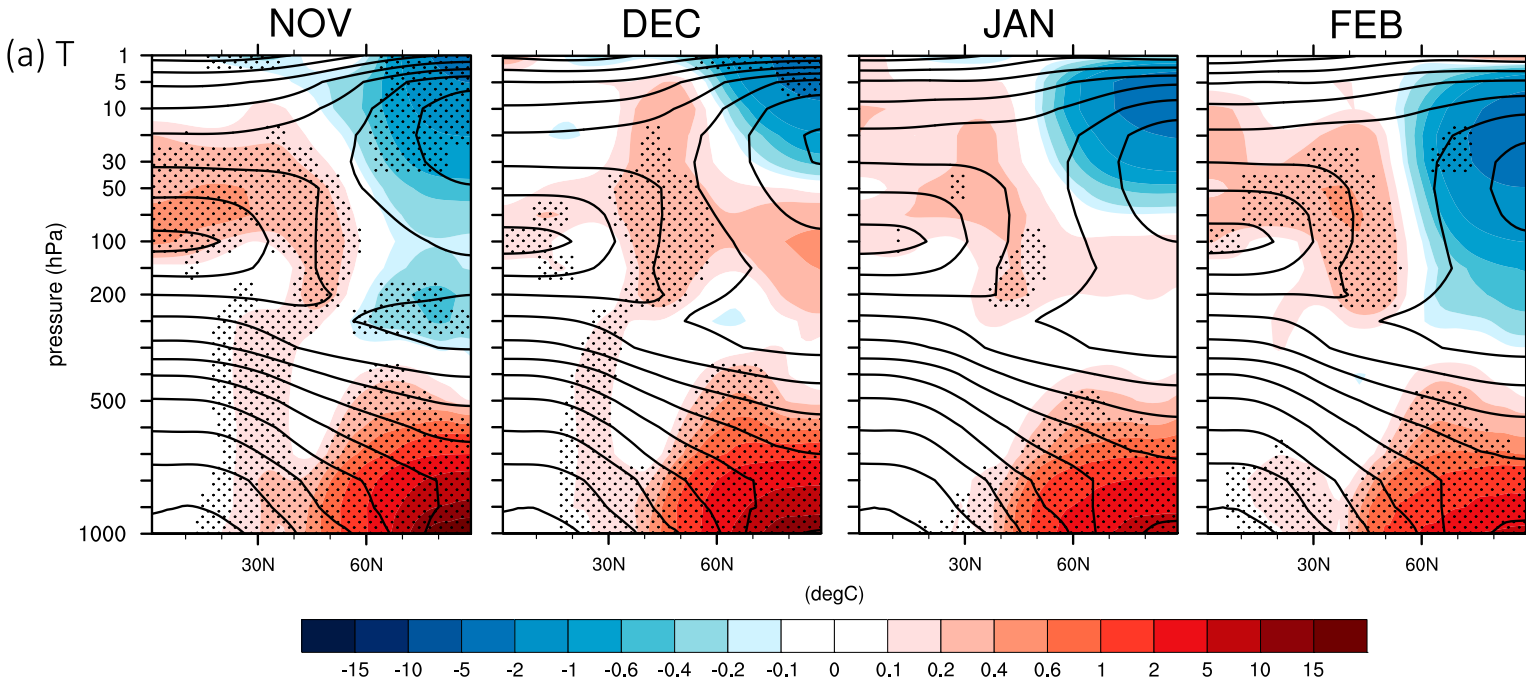

(b) Z
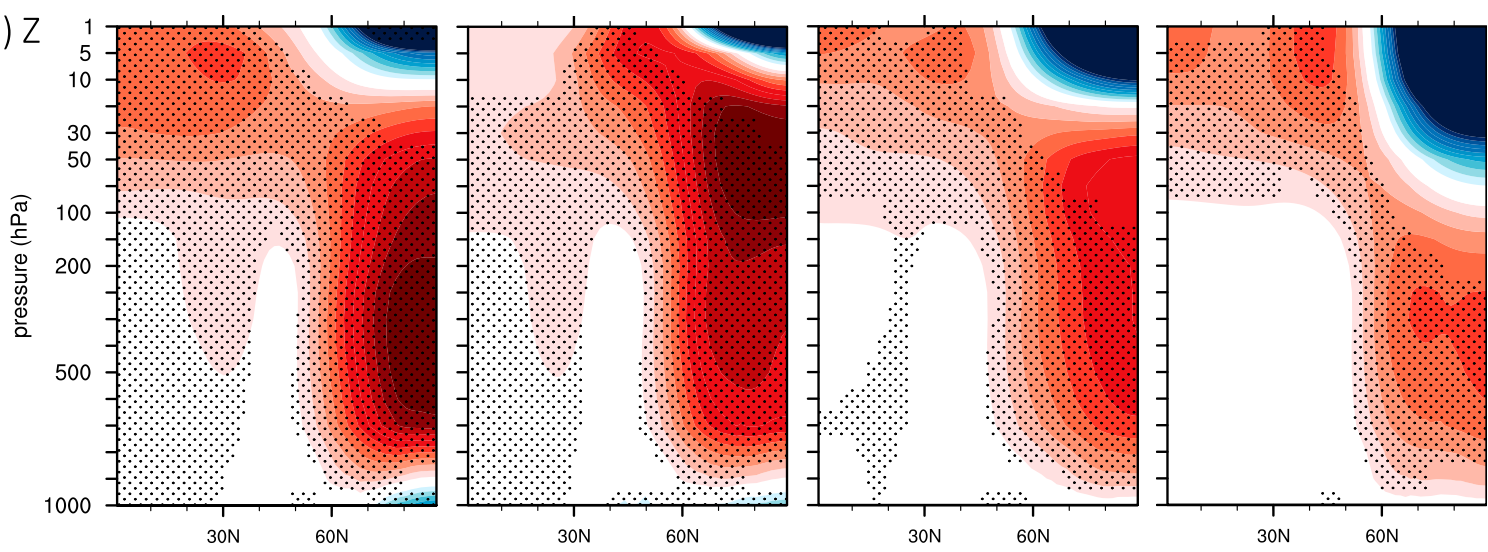

(m)

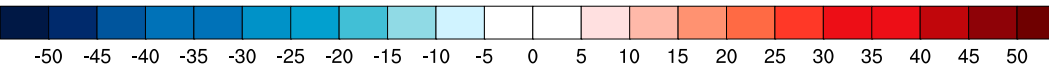

(c) U

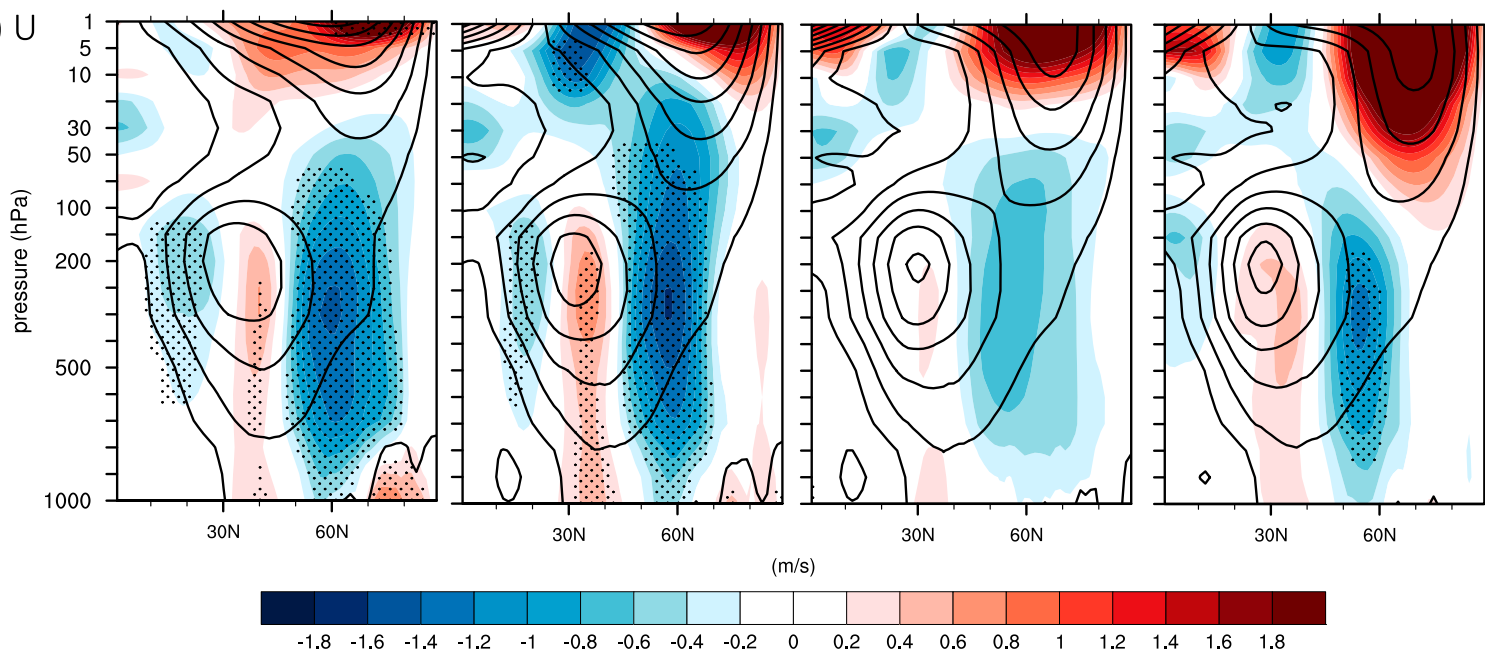

FIG. 4. Monthly responses of zonal-mean (a) temperature $T\left({ }^{\circ} \mathrm{C}\right),(\mathrm{b})$ geopotential height $Z(\mathrm{~m})$, and (c) zonal wind $U\left(\mathrm{~m} \mathrm{~s}^{-1}\right)$ from November to February. Contours in (a) show zonal-mean temperature control climatology (interval: $10^{\circ} \mathrm{C}$ ). Contours in (c) show zonalmean zonal wind control climatology (interval: $8 \mathrm{~m} \mathrm{~s}^{-1}$ ). Note the nonlinear scale in (a). Dots indicate statistically significant grid points with $p$ values $<0.05$ using the two-sided Student's $t$ test and false discovery rate (Wilks 2016). 
following months, it is confined to the upper stratosphere but the response is hardly significant. Over the polar cap, the geopotential height increases up to the midstratosphere around $20 \mathrm{hPa}$ (Fig. 4b). The atmospheric response north of $55^{\circ} \mathrm{N}$ is baroclinic in November-December, with negative anomalies near the surface and positive anomalies above. The strongest increase in geopotential height of more than $50 \mathrm{~m}$ occurs in the midtroposphere around $600 \mathrm{hPa}$ in November and it reaches the stratosphere in December. In January-February, the positive anomalies from the surface to the lower stratosphere decrease by a factor of 2 with respect to December, and they are confined to lower levels in February.

Around $30^{\circ} \mathrm{N}$, a warming 10 times smaller than over the Arctic occurs in the tropospheric column in NovemberDecember (Fig. 4a), in line with the weak increase in geopotential height (Fig. 4b). This effect is consistent with an enhanced tropical convection due to warmer tropical sea surface temperatures (not shown). This enhanced tropical convection in response to Arctic sea ice loss might be due to ocean-atmosphere coupling, involving changes in energy flux exchanges at the air-sea interface at monthly time scale. This differs from coupled studies that have investigated the decadal or equilibrium response to Arctic sea ice loss, in which changes in ocean dynamics were additionally involved (e.g., Deser et al. 2015; Screen et al. 2018; Wang et al. 2018). A warming is also found in the lower tropical stratosphere, from the equator to $60^{\circ} \mathrm{N}$ for each month. Consistent with the warming of the tropical troposphere and stratosphere, we find that the geopotential height south of $60^{\circ} \mathrm{N}$ largely increases from the midtropospheric to the upper stratospheric levels (Fig. 4b).

These changes in temperature and pressure from the polar cap to the tropics and from the troposphere to the stratosphere are associated with changes in the position and intensity of the midlatitude westerly winds, the subtropical jet stream, and the polar vortex. We find a weakening of the zonal-mean zonal wind centered at $60^{\circ} \mathrm{N}$ in the troposphere during every month (Fig. 4c), which is consistent with an increase of the polar cap geopotential height and thermal wind balance. It is largest in December with values reaching up to $-1.6 \mathrm{~m} \mathrm{~s}^{-1}$ (about $10 \%$ of the climatological value). The subtropical jet stream is strengthened and narrowed in November-December with a positive response in its core and a negative one at both flanks. At low levels, the midlatitude westerly winds are shifted southward. In January, the zonal-mean zonal winds are hardly affected, but in February we find a slight southward shift of the subtropical jet stream and of the midlatitude westerly wind belt. The zonal wind response near the tropopause and at low levels is zonally symmetric and it affects the North Atlantic and North Pacific jet streams similarly, consistent with the results reported in Deser et al. (2015) and Oudar et al. (2017), with an eastward shift of both jets (not shown). This is also in agreement with the study of Ronalds et al. (2020), who found an eastward shift of the North Pacific jet in response to Arctic sea ice loss. Moreover, the zonal wind response near the tropopause and at low levels resembles the negative NAM pattern, with spatial correlations of about 0.60 for the four months with respect to the NAM pattern obtained from CTL. The storm tracks response, computed using the variance of the meridional wind component at $500 \mathrm{hPa}$, is consistent with the midlatitude westerly wind response (Fig. 5). In general, synoptic activity largely decreases over the Arctic and the midlatitudes in response to Arctic sea ice decline, in line with what has been reported in previous studies (Screen et al. 2018). The largest storm track response is observed from November to December, in agreement with the zonal-mean zonal wind response. A slight but significant increase of storm tracks between $20^{\circ}$ and $40^{\circ} \mathrm{N}$ is found in the Pacific in November, December, and February, and in the Atlantic in December, indicating a southward shift these months. This is consistent with the results of Magnusdottir et al. (2004), Semmler et al. (2016), and Oudar et al. (2017).

We find that the weakening of the zonal-mean zonal winds centered at $60^{\circ} \mathrm{N}$ in the troposphere extends up to the lower part of the polar vortex core in the stratosphere at $10 \mathrm{hPa}$ in December, in line with the geopotential height response (Figs. 4b,c), but with significant values up to $50 \mathrm{hPa}$. In the upper stratosphere, the polar vortex is shifted northward that month, with significant negative anomalies on the equatorward side and positive ones on the poleward side above $10 \mathrm{hPa}$. The following months, the polar vortex is strengthened but this response does not exceed the internal variability in the stratosphere represented in the model, leading to a response that is not statistically significant. Note that the weakening of the lower part of the polar vortex is only visible in December. Seasonal averages can mask the vertical extension of this weakening as it is only visible up to $50 \mathrm{hPa}$ during the autumn season when using 3-month averages (Fig. S2). The weakening up to $10 \mathrm{hPa}$ found in December is consistent with what has been reported in some previous modeling studies, albeit with a different timing for the response. For instance, Peings and Magnusdottir (2014) found that the weakening of the lower part of the polar vortex occurs in February, while Kim et al. (2014) have detected it in January-February, and Sun et al. (2015) in December-February. A possible explanation for this different timing could be the discrepancies in sea ice forcings among the various modeling protocols leading to different timings for the Arctic amplification response and hence different timings for the stratospheric response. The different responses could also be related to a different representation of the stratosphere in the models (mean state and internal variability) or more generally to the low signal-tonoise ratio of the atmospheric response to Arctic sea ice loss.

In the polar stratosphere, stratospheric sudden warming (SSW) events can also occur when the weakening of the zonal winds is strong enough to cause their reversal (Butler et al. 2015). To analyze the changes in the occurrence of SSW events in our experiments, we define a SSW index based on the method of Charlton and Polvani (2007). We find that the weakening of the polar vortex in December is too weak to change the SSW frequency. Note that such changes in the SSW frequency could not be detected even in studies with a stronger polar vortex response to Arctic sea ice loss or to Arctic amplification (e.g., Wu and Smith 2016).

Our results stress the importance of investigating the month-tomonth evolution of the atmospheric circulation response to Arctic sea ice loss. We showed that the tropospheric circulation response can be decomposed into two steps. First, we found that the circulation changes are largest in November-December, with a narrowing of the subtropical jet stream and a southward shift of 


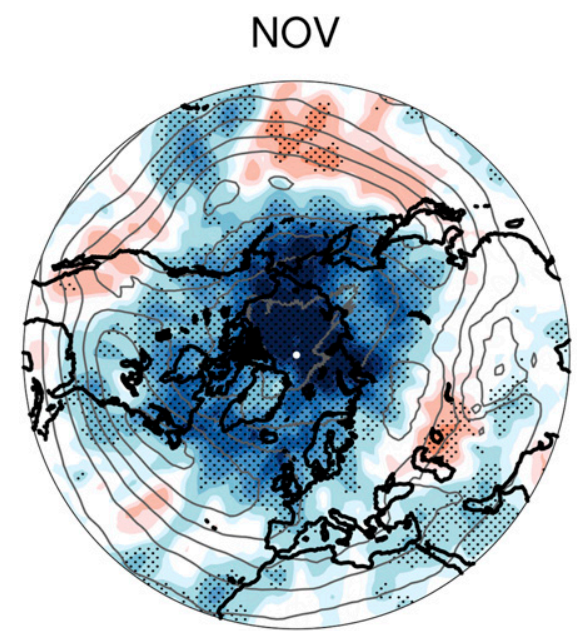

JAN

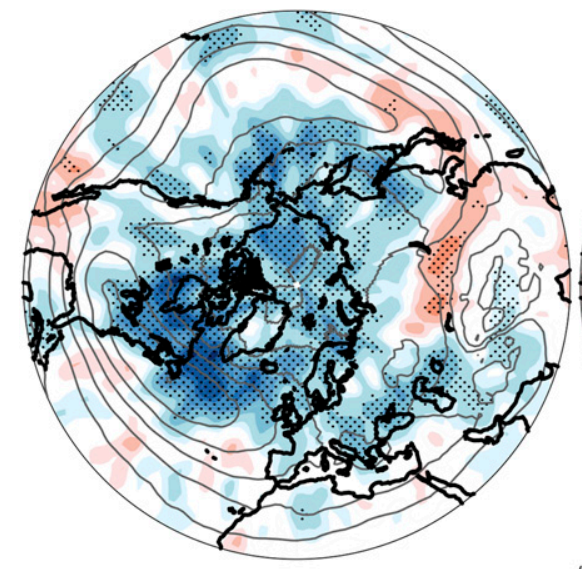

$\mathrm{m} / \mathrm{s}$

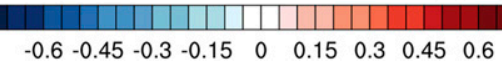

FIG. 5. Monthly response of the variance of the meridional wind at $500 \mathrm{hPa}\left(\mathrm{m} \mathrm{s}^{-1}\right)$, filtered at synoptic scales (2-8 days). Contours: control climatology (interval: $1 \mathrm{~m} \mathrm{~s}^{-1}$ ). Dots indicate statistically significant grid points as described in Fig. 4. the low-level midlatitude westerly winds. Then, we showed a slight equatorward shift of the subtropical jet stream and midlatitude westerlies in February. We find that the circulation in the stratosphere does not change much in response to Arctic sea ice loss, with only a slight weakening of the lower part of the polar vortex.

\section{2) NEAR-SURFACE RESPONSE}

In this section, we describe the spatial evolution of the near-surface atmospheric response to Arctic sea ice decline. Figures $6 \mathrm{a}-\mathrm{c}$ show the monthly responses of near-surface air temperature (SAT), sea level pressure (SLP), and geopotential height at $500 \mathrm{hPa}(\mathrm{Z} 500)$.

Arctic amplification resulting from the imposed sea ice perturbation spreads to midlatitudes over North America, Europe, and Asia (Fig. 6a) and is maximum in November as previously shown in Fig. 4a. We find that this increase in energy amount and temperature over the Arctic is also linked with an increase in local precipitations, especially over the Arctic Ocean (not shown). The Arctic amplification over the Arctic ocean reaches its maximum in November with a magnitude of $25^{\circ} \mathrm{C}$ and spreads to adjacent continents over Siberia and North America with a warming of about $6^{\circ} \mathrm{C}$ in November-December in the Arctic region. Arctic sea ice loss also affects surface temperatures over land up to the midlatitudes. From November to February a warming of $1{ }^{\circ} \mathrm{C}$ is found over a great part of Europe and North America (Fig. 6a). Moreover, a cooling of less than $1^{\circ} \mathrm{C}$ is observed over central Asia from December to February. The temperature response is consistent with the result of Deser et al. (2016a), who used an ocean-atmosphere coupled configuration. The wintertime cooling over central Asia is also consistent with some other modeling studies (Peings and Magnusdottir 2014; Smith et al. 2017) and with the WACC pattern seen in observations, although less spatially extended (Mori et al. 2014). Note that using inappropriate seasonal 

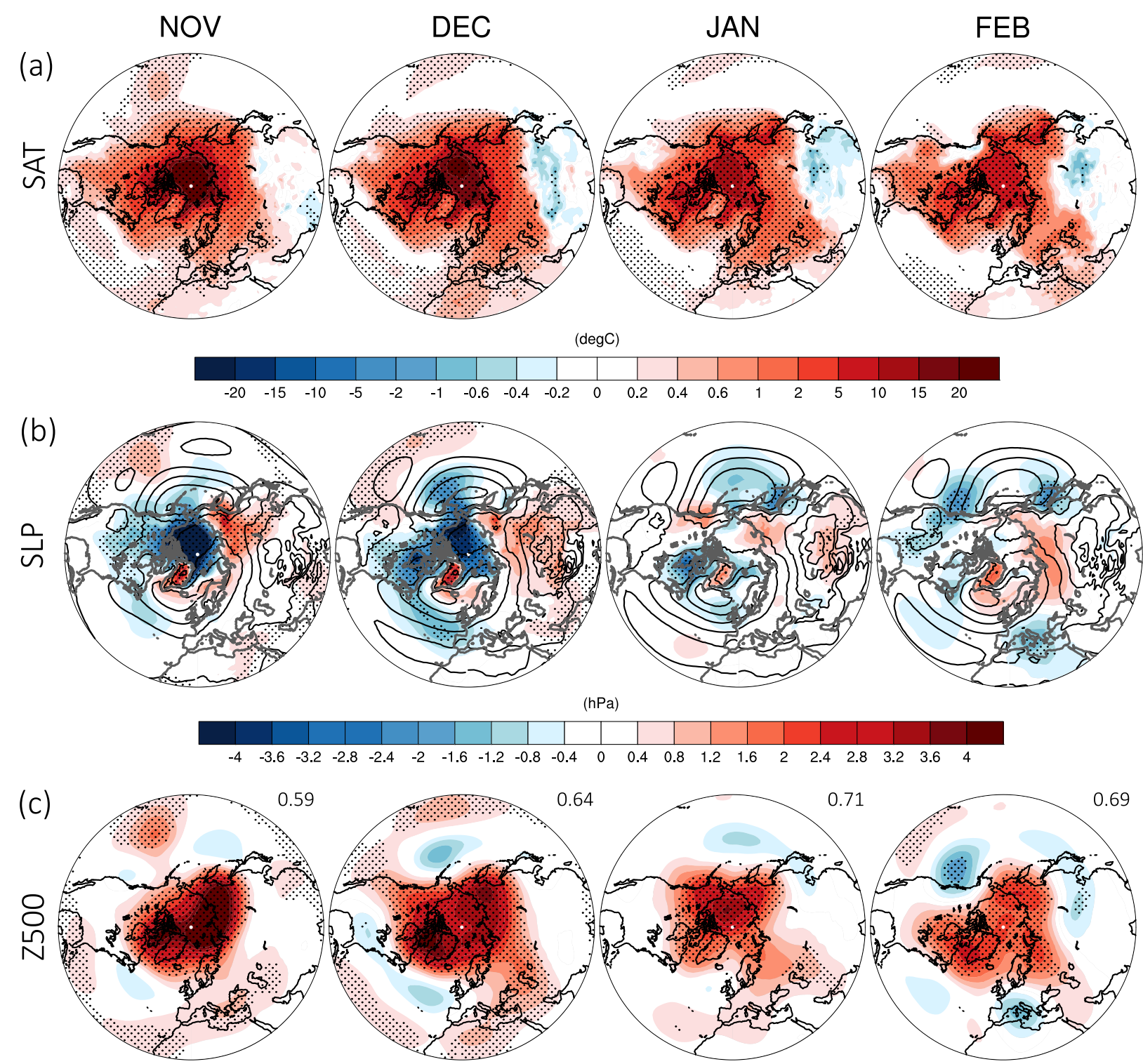

(m)

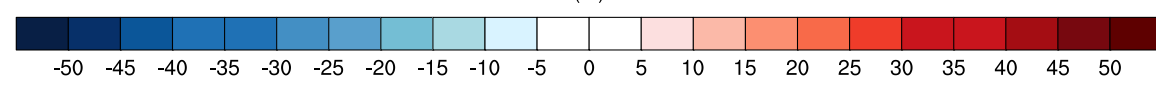

FIG. 6. Monthly responses of (a) near-surface air temperature (SAT; $\left.{ }^{\circ} \mathrm{C}\right),(\mathrm{b})$ sea level pressure (SLP; hPa), and (c) 500-hPa geopotential height (Z500; m) from November to February. Contours in (b) show SLP control climatology (interval: $5 \mathrm{hPa}$ ). Note the nonlinear scale in (a). The numbers at the top right of (c) show the spatial correlation of the Z500 response with the spatial pattern of Z500 associated with the negative NAM computed in the CTL experiment. Dots indicate statistically significant grid points as described in Fig. 4.

averages would mask the cooling over central Asia that first emerges in December (Fig. S2). The robustness of the atmospheric response over the midlatitudes also depends on the number of members considered (Fig. S3). If we had considered only 40 members, which corresponds to the initial H2020PRIMAVERA protocol that this study is part of, we would have had a stronger and more spatially extended cooling over central Asia than with more members, and no significant warming over eastern Europe and North America (Fig. S3). Including more members like we did in this study shows that the cooling over central Asia is intermittent and difficult to detect due to the large internal variability.

The largest pressure anomalies over the Northern Hemisphere occur in November-December, in phase with the maximum 
SAT response over the Arctic (Figs. 6b,c). As seen in Fig. 4b, the pressure response over the Arctic Ocean shows a typical baroclinic pattern during these months when the energy absorbed by the atmosphere is the strongest, with a cyclonic response at sea level and anticyclonic response at $500 \mathrm{hPa}$. This is associated with ascending warmer air over the regions of sea ice loss leading to a negative pressure anomaly at sea level and an increased geopotential height caused by thermal expansion (Osborne et al. 2017). The SLP anomalies in November-December depict an intensification of the northeastern part of the Siberian high, a weakening of the Icelandic low, and a reduction of SLP over North America. In December, there is in addition a noticeable cyclonic response over the Aleutian low and above the North Atlantic. These results are in good agreement with other recent coupled model studies reported by Screen et al. (2018), suggesting that this late-autumn response is robust. In JanuaryFebruary, the pressure response is very weak at sea level but it is still large and statistically significant at $500 \mathrm{hPa}$ (Figs. 6b,c). The pattern correlation between the Z500 response and the negative NAM pattern remains high during the four months. The response projects well onto the negative NAM pattern in particular in February with significant negative anomalies in the midlatitudes (see Fig. 1 in Baldwin and Dunkerton 1999). We note that the intensification of the Siberian high, which is expected to favor a southward advection of cold Arctic air, is consistent with the cooling found in central Asia in December-January. However, temperature anomalies over midlatitude regions can result from a complex interaction between the effects of dynamical changes and thermodynamical changes due to Arctic amplification. We further investigate this link in the next section and analyze the mechanisms of the SAT response over the three following midlatitude regions of interest: North America (defined as $30^{\circ}-$ $\left.60^{\circ} \mathrm{N}, 140^{\circ}-50^{\circ} \mathrm{W}\right)$, Europe $\left(35^{\circ}-60^{\circ} \mathrm{N}, 15^{\circ} \mathrm{W}-45^{\circ} \mathrm{E}\right)$, and central Asia $\left(30^{\circ}-50^{\circ} \mathrm{N}, 70^{\circ}-125^{\circ} \mathrm{W}\right)$.

\section{c. Mechanisms of the temperature response over land: Dynamical and residual components}

To explain the mechanisms driving the temperature anomalies over North America, Europe, and central Asia in response to Arctic sea ice loss and extract the role of sea level circulation changes, we decompose the SAT response into two contributions, using the dynamical adjustment method introduced in section $2 \mathrm{c}$. Recall that the first one is the indirect or dynamical contribution that is due to sea level circulation changes occurring in response to Arctic sea ice decline. The second one is the direct or residual contribution. It can be related either to the advection of anomalous warmer oceanic air masses by the climatological flow near the surface or to local changes in the surface energy budget. Figure 7 illustrates the two contributions of the SAT response obtained with this method. The ratio of the residual contribution with respect to the total one is represented in the last row to visualize the relative amplitude of the two components.

\section{1) NORTH AMERICA}

From November to February, the warming found over North America can be explained by a combination of the two components: the residual component, which dominates the total response over the northern part, and the dynamical component, which dominates over the southern part (Fig. 7c). The dynamically induced warming is linked to a cyclonic change in the atmospheric circulation (Figs. 7a and 6b). Indeed, the anomalous surface wind conditions tend to bring milder oceanic air from the North Atlantic toward the southwest from November to February and, in addition, milder air from the south in November and February. Note that in January, the cyclonic anomaly is restricted to the eastern part of North America while an anticyclonic anomaly is found over the western part. Together, they favor an advection of cold Arctic air toward the southwest, which explains the cooling over the western part of North America that is dynamically induced. Although the anticyclonic response is not statistically significant (Fig. 6b), this cooling counteracts the residual warming, yielding a response that is close to zero in the western part of North America in January (Fig. 6a and white areas in Fig. 7c).

The residual warming obtained over North America during the four months is likely due to the southward advection of warm Arctic air resulting from the temperature increase in response to sea ice loss over the central Arctic Ocean, Beaufort Sea, and Hudson Bay (Fig. 8). The residual warming over North America could also be explained by an advection toward the east of warmer oceanic air masses over the eastern North Pacific. This is consistent with the positive SST anomalies in this region shown in Fig. 8. This residual warming is more pronounced in the northern part of the North American region. It generally exceeds the dynamically induced warming by more than $70 \%$ (Fig. $7 \mathrm{c}$ ). Note that an increase in the residual SAT over this part of the region could also be linked to an increase in the net downward surface energy budget that is explained both by an increase in net downward sensible heat flux and net downward longwave flux in November-December (not shown).

\section{2) EUROPE}

The warming over Europe is largely explained by the residual component in November, and by both dynamical and residual components during the other months (Fig. 7c). The residual warming obtained from November to February is likely due to the advection by the westerlies of warmer oceanic air masses over the western North Atlantic and European west coast in response to Arctic sea ice loss (Fig. 8). Note that the European warming could also be related to an increase in the net downward long wave flux in November (not shown).

The warming over Europe can also be explained by dynamical changes in December and January. It is likely related to the advection toward the north east by the anomalous flow of air masses of oceanic origin, which are relatively mild during these months compared to cold and dry land surface temperatures. In December, the residual warming gets larger than the dynamically induced warming (especially in the northeastern part). In January however, the dynamically induced warming dominates the SAT response, especially over western Europe (Fig. 7c). It could be explained by the circulation changes occurring above the North Atlantic and over Europe (Fig. 6b) although these are weak and not statistically significant. In February, the cyclonic response over the Mediterranean Sea favors a warming over the eastern part of Europe and a cooling 

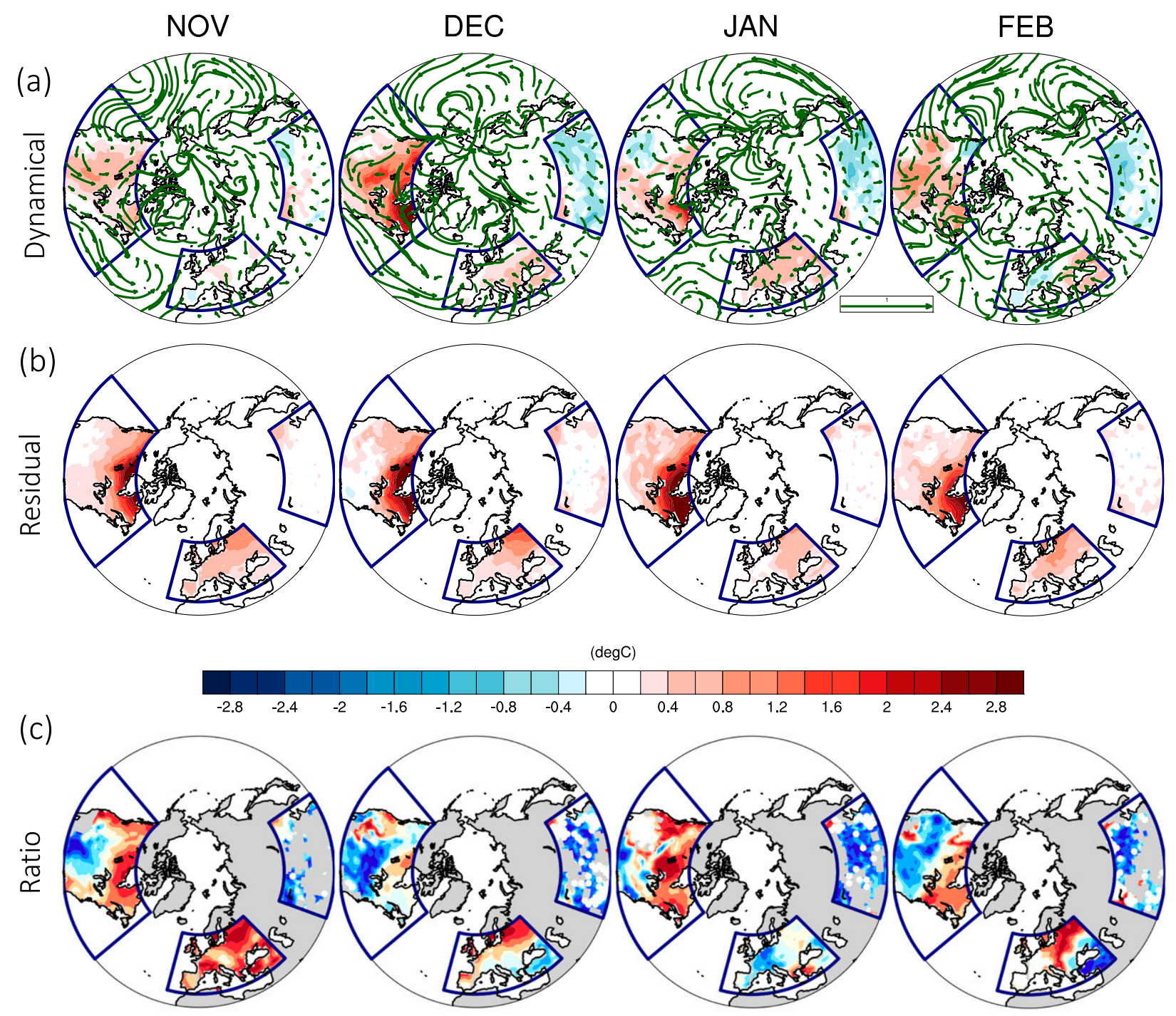

(\%)

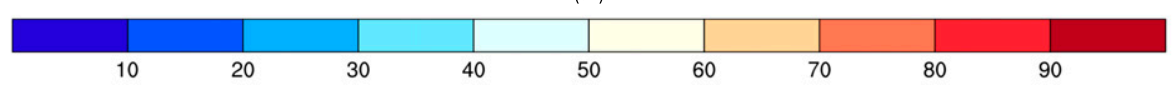

FIG. 7. (a) Dynamical and (b) residual contributions of the near-surface air temperature response over North America, Europe, and central Asia, from November to February $\left({ }^{\circ} \mathrm{C}\right)$. Contours in (a) show surface winds response ( 1 unit: $1 \mathrm{~m} \mathrm{~s}^{-1}$ ), associated with the SLP response used to reconstruct the dynamically induced SAT. Note the different color scale than in Fig. 6a. (c) Ratio of residual vs total SAT response (\%), computed as $\mid$ residual $\mid /(\mid$ residual $|+|$ dynamical $\mid)$. Gray shading inside the three regions in (c) indicates masked areas where both components and the total response are weak (below $0.2^{\circ} \mathrm{C}$ ). White full dots in (c) show areas where both components cancel each other. Note that red shading $(>50 \%)$ in (c) corresponds to areas where the residual component dominates the total response and blue shading $(<50 \%)$ where the dynamical component dominates the total response.

over the western part. This cooling counteracts the residual warming over western Europe, which leads to the absence of a SAT response over this part of Europe in February (Fig. 6a and white areas in Fig. 7c).

\section{3) Central Asia}

While near-surface air temperatures over North America and Europe increase in November in response to the Arctic sea ice forcing imposed in our experiments, we find no change in SAT over central Asia during this month (Fig. 6a). Rather than due to an offset between the two components, this can be explained both by the lack of a dynamical and a residual response in the vast majority of the region (gray areas in Fig. 7c).

From December to February however, the cooling found over central Asia is entirely explained by changes in circulation occurring in response to the Arctic sea ice reduction. More 

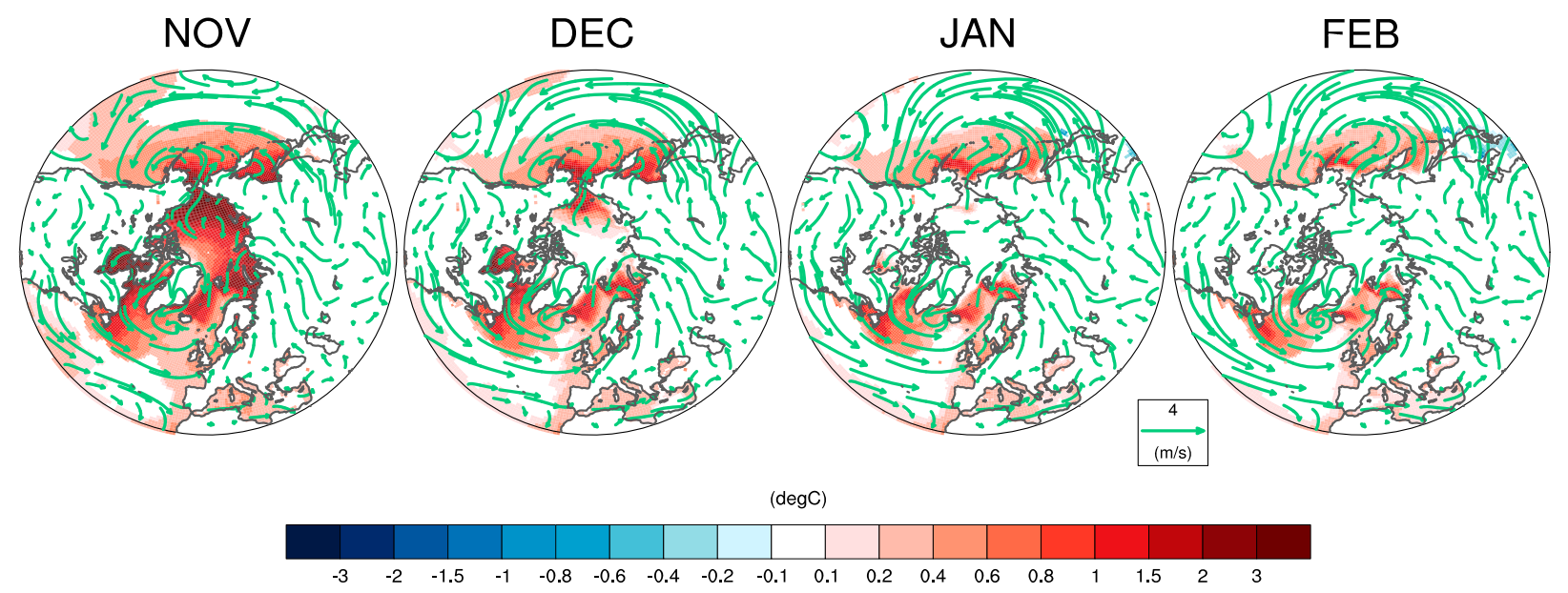

FIG. 8. Monthly response of sea surface temperature (SST; ${ }^{\circ} \mathrm{C}$ ) in the Arctic and midlatitudes from November to February. Vectors: surface winds climatology in CTL (1 unit: $4 \mathrm{~m} \mathrm{~s}^{-1}$ ). Only the statistically significant grid points as described in Fig. 4 are shown.

specifically in December, anticyclonic anomalies found over the Siberian high (i.e., an intensification of the Siberian high) and over its northeastern part, favor a southwestward advection of cold polar air masses into central Asia, which explains the dynamically induced cooling. In January, the strengthening of the Siberian high is located farther south, and it contributes, together with the weak anticyclonic response over northeastern Siberia and the significant cyclonic response over the Sea of Okhotsk, to the dynamical cooling over central Asia. In February, the combination of the significant cyclonic response over the Sea of Okhotsk and the anticyclonic response over northern Siberia also leads to a significant dynamically induced cooling, although less spatially extended than during the previous month. Note that from December to February, some areas where a small residual warming counteracts the dynamical cooling are found. This leads to a lack of total SAT response in these areas (white areas in Fig. 7c).

\section{d. Mechanisms of the atmospheric circulation response: Role of troposphere-stratosphere interaction}

We have shown in section $3 b$ that the atmospheric circulation response to Arctic sea ice loss extends up to the lower stratosphere and that tropospheric circulation can evolve differently from late autumn to early winter. In this section we discuss the role of upward propagation of the tropospheric response to the stratosphere until $10 \mathrm{hPa}$, and whether the stratospheric response could play a role in the circulation changes occurring at lower levels.

Figure 9 shows the evolution of the polar cap $\left(60^{\circ}-90^{\circ} \mathrm{N}\right)$ daily geopotential height response from October to March. This diagnostic is an indication of the NAM index response throughout the troposphere and stratosphere, with positive (negative) values corresponding to a negative (positive) NAM index (Baldwin and Dunkerton 2001; Peings and Magnusdottir 2014; Kim et al. 2014; Sun et al. 2015). The geopotential height response is baroclinic over the polar cap from November to early December, as described in section $3 b$, with negative anomalies at the surface and positive anomalies above. The evolution of the geopotential height anomalies suggests that the strong positive anomalies in the stratosphere in mid-December originate from the troposphere in early December. We hence hypothesize that the weakening of the lower part of the polar vortex is due to an upward propagation of planetary-scale waves from the troposphere. The positive anomalies in the stratosphere persist until early January. Then, they are confined to the troposphere and near the surface the following months, which indicates a positive NAM response. Note that the anomalies at the surface remain quite weak, in agreement with the weak SLP response that was found in January and February (Fig. 6b).

To better understand the mechanism behind these possible troposphere-stratosphere interactions, we analyze the response of the EP flux and its divergence, using the formulation defined in section 2c. In agreement with Fig. 9, we find that the

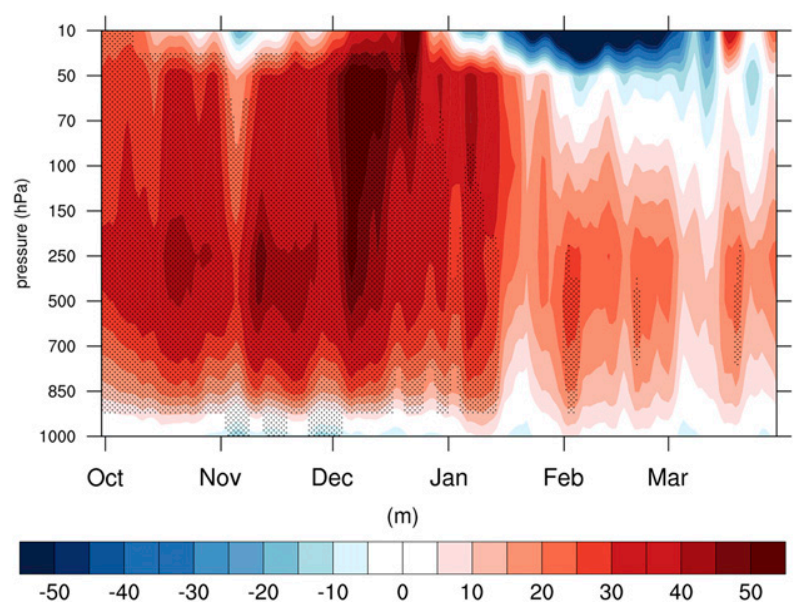

FIG. 9. Polar cap time-pressure cross section of the daily geopotential height response $(\mathrm{m})$, averaged north of $60^{\circ} \mathrm{N}$, from October to March. Dots indicate statistically significant grid points as described in Fig. 4. 


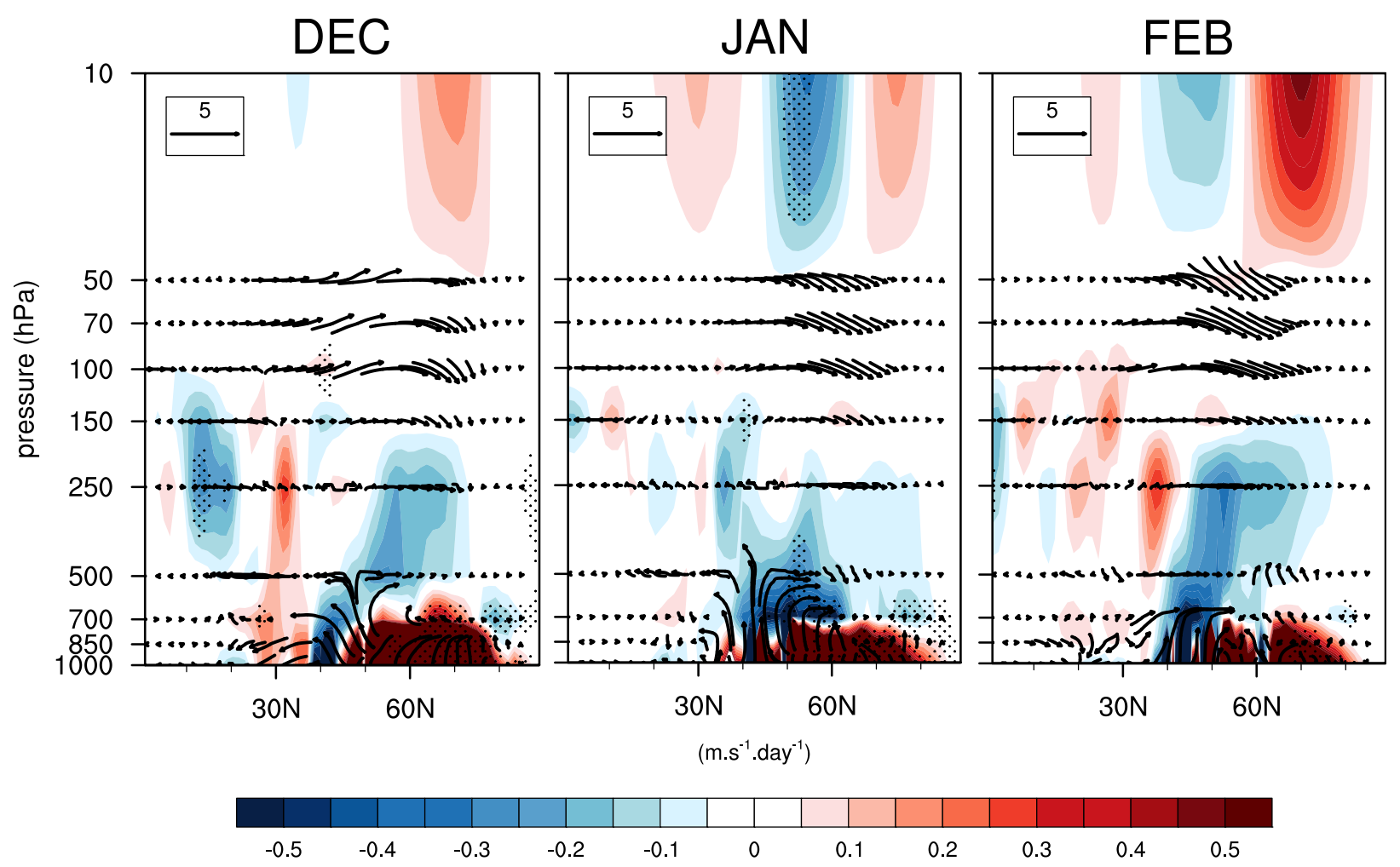

FIG. 10. Monthly response of the Eliassen-Palm flux vectors (horizontal component in $\mathrm{m}^{2} \mathrm{~s}^{-2}$ and vertical component in kg $\mathrm{m} \mathrm{s} \mathrm{s}^{-4}$ ) and divergence $\left(\mathrm{m} \mathrm{s}^{-1} \mathrm{day}^{-1}\right.$; color shading) from December to February. The vectors are scaled according to the convention described in Edmon et al. (1980) and by a magnification factor of 3 above $100 \mathrm{hPa}$ to extend the vectors in the stratosphere. See section $2 \mathrm{c}$ in the main text for more details. Dots indicate grid points where the divergence is statistically significant as described in Fig. 4.

emerging upward propagating signal from the troposphere to the stratosphere occurs in December. Hence, we only show the response of the EP flux starting in December (Fig. 10).

An enhanced upward wave activity is found in December around $45^{\circ} \mathrm{N}$ in the lower troposphere and in the lower stratosphere (Fig. 10). Farther north around $70^{\circ} \mathrm{N}$, we find a reduction of upward wave activity in the stratosphere. Above $700 \mathrm{hPa}$ in the troposphere, a convergence of EP flux occurs around $60^{\circ} \mathrm{N}$, consistent with weaker westerlies (Fig. 4c). At $250 \mathrm{hPa}$, the divergence around $30^{\circ} \mathrm{N}$ and convergence around $15^{\circ} \mathrm{N}$ are consistent with the narrowing of the subtropical jet stream (Fig. 4c). The analysis of the meridional eddy heat flux, proportional to upward wave activity (e.g., Shaw et al. 2014; García-Serrano et al. 2015), reveals that the main sources of upward wave propagation at $850 \mathrm{hPa}$ are located over the Siberian high, the Gulf of Alaska, western Europe, and Baffin Bay (not shown). This is in agreement with previous studies that showed that the Siberian high region appears to be a key region for the upward propagation of the response from the troposphere to the stratosphere (e.g., Labe et al. 2019).

In January, a significant convergence of these planetary waves occurs in the lower part of the polar vortex core at $10 \mathrm{hPa}$ (Fig. 10). There is also a downward stratospheric wave flux and a downward movement of the EP flux convergence between $45^{\circ}$ and $90^{\circ} \mathrm{N}$ toward the troposphere in JanuaryFebruary. Further, there is a convergence of EP flux in these two months in the troposphere, which is coherent with the deceleration of the westerly winds that was shown in Fig. 4c. Southward of $40^{\circ} \mathrm{N}$, there is a divergence of EP fluxes at $250 \mathrm{hPa}$ in February, which is also consistent with the intensification of the subtropical jet stream core occurring that month (Fig. 4c).

A possible dynamical explanation for the enhanced upward propagation of planetary waves is the constructive interference that can occur between the forced planetary waves and the mean flow (Garfinkel et al. 2010). We show in Fig. 11 the departure from the zonal mean of the geopotential height response at $300 \mathrm{hPa}$ in December and January for the first two wavenumbers, which represent the response of the planetaryscale waves. A constructive interference between the forced and the climatological planetary waves is found in the midlatitudes between $30^{\circ}$ and $50^{\circ} \mathrm{N}$ in December and January, in line with the upward propagating response. The upward propagation in December, which was shown in Figs. 9 and 10, is likely driven by the constructive interference for wavenumber 2 in the midlatitudes, and the weak interference for wavenumber 1 is consistent with the weak stratospheric response (Fig. 4c). In January, we find a constructive interference for both wavenumbers, in agreement with the convergence of 

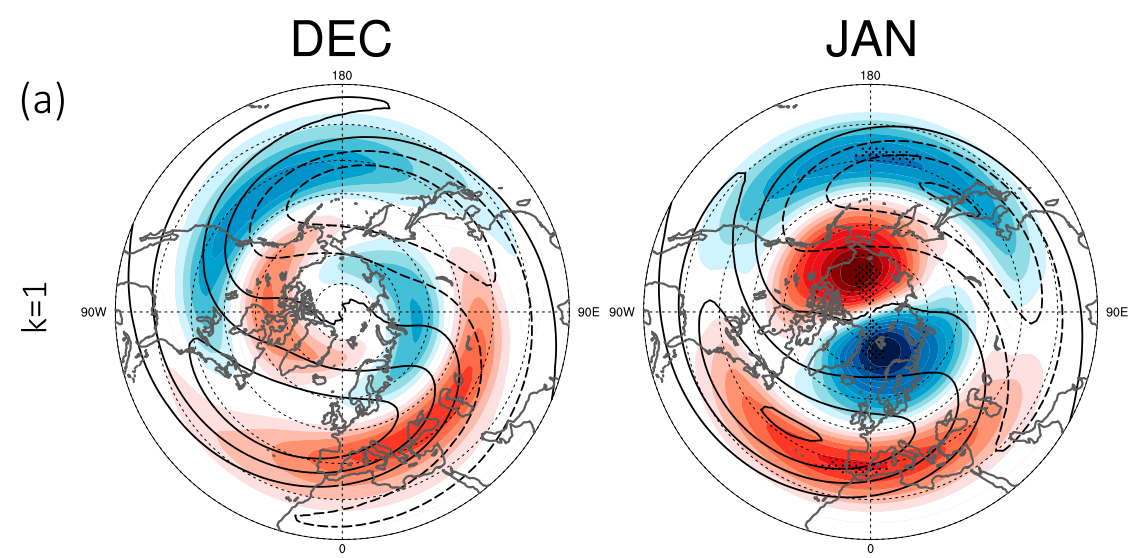

(b)

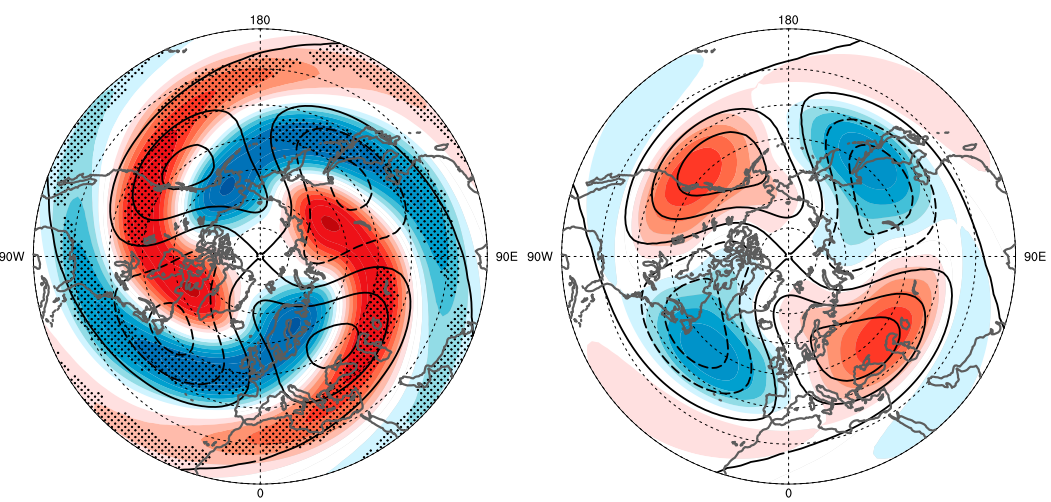

(m)

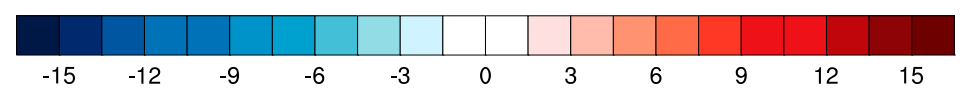

FIG. 11. Monthly response of the $300-\mathrm{hPa}$ geopotential height zonal anomaly $(\mathrm{m})$ for (a) zonal wavenumber $1(k=1)$ and (b) zonal wavenumber $2(k=2)$ in December and January, obtained by a Fourier decomposition of the zonal departure of the geopotential height using monthly means. Contours show control climatology (interval: $50 \mathrm{~m}$ ); dotted lines are negative values. Dots indicate statistically significant grid points as described in Fig. 4.

planetary waves shown in Fig. 10. While the convergence of the waves in the stratosphere is found in January (Fig. 10), the most intense weakening of the lower part of the polar vortex occurs in December and not in January (Fig. 4c). This might be related to the large variability of the stratosphere in January that could mask the influence of planetary waves on the zonal mean flow that month.

Our analysis suggests that the weakening of the lower part of the polar vortex in December probably results from the enhancement of upward planetary wave activity from the troposphere to the stratosphere. The polar vortex response remains however weak in our experiments, which is likely related to the weak constructive interference between the forced and the climatological planetary waves. The anomalies in the troposphere and at the surface in January-February could either be explained by the delayed downward influence of the stratospheric anomalies, that however seem to be small in our experiments, or solely by tropospheric processes associated with simultaneous sea ice loss. Dedicated experiments would be needed to distinguish these two effects.

\section{e. Impact on cold extreme temperatures}

In this section, we investigate the impacts of Arctic sea ice loss on extreme weather with a focus on the three midlatitude regions highlighted in section 3c: North America, Europe, and central Asia. We analyze the cold extreme temperature response and the changes in temperature variability in November-December and January-February.

Changes in cold extreme temperatures are represented in Fig. 12 and are computed as the response of the 5th quantile of daily minimum SAT obtained from the whole distribution of 200 members. The spatial patterns of the cold extreme and mean SAT responses are very similar (Figs. 12 and 6a). Over North America and Europe, minimum daily temperatures largely increase from November to February. The warming can reach $5^{\circ} \mathrm{C}$ (about $15 \%$ change) over the midlatitudes in eastern Europe and in North America in November-December. The largest decrease in minimum daily temperature occurs over central Asia in February and it reaches $1.5^{\circ} \mathrm{C}$, which represents a change of less than $5 \%$. These results suggest that Arctic sea ice 

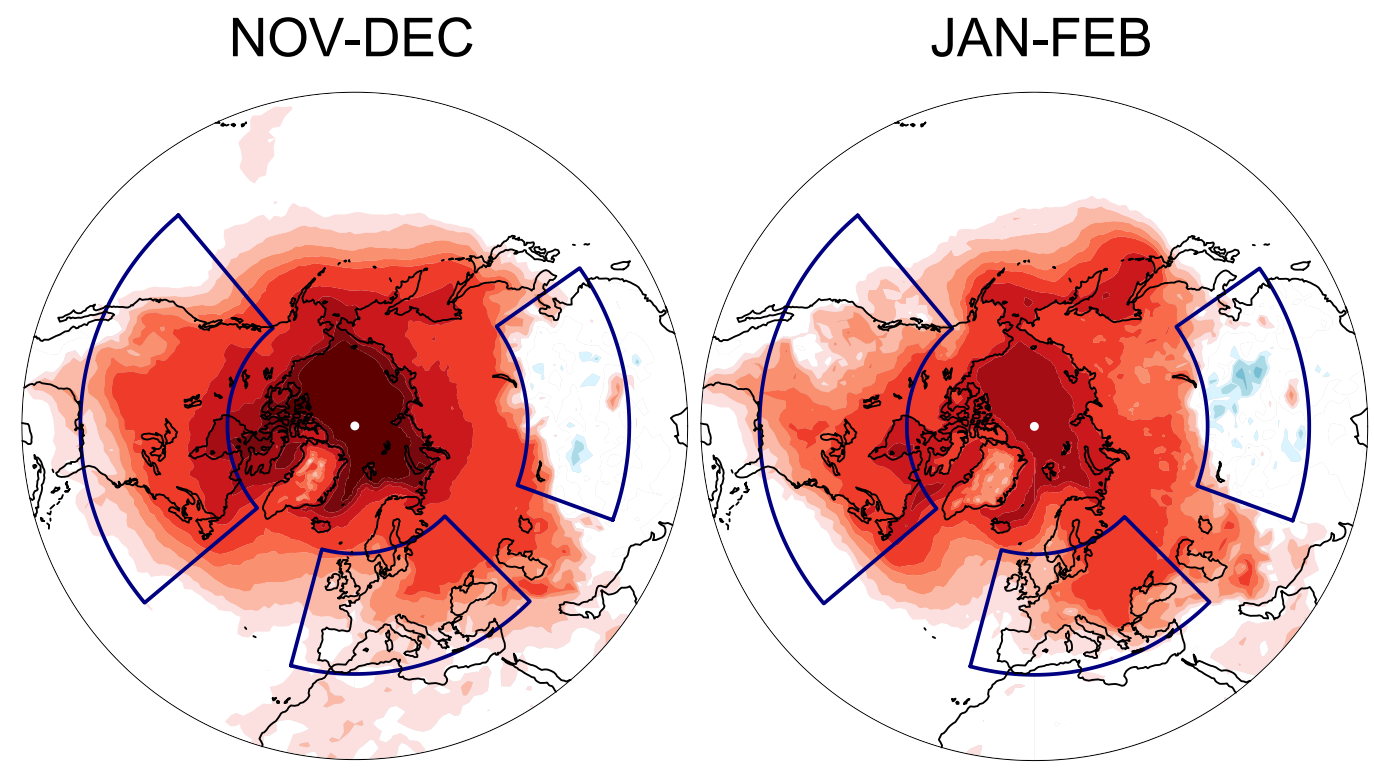

$(\operatorname{deg} \mathrm{C})$

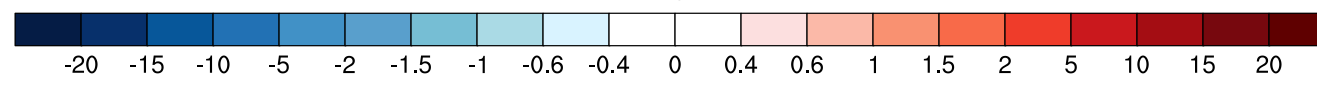

FIG. 12. Response of the 5 th quantile of daily minimum surface air temperature $\left({ }^{\circ} \mathrm{C}\right)$ for November-December and January-February, computed over the whole 200-member distribution.

loss can have a significant impact on midlatitude extreme temperatures. Moreover, we find a reduction of SAT variability over most of the Northern Hemisphere in response to sea ice decline (Fig. 13), which is opposite to the hypothesis of Francis and Vavrus (2012) that would lead to an increase in extreme temperature variations (Barnes and Screen 2015). The largest decrease occurs over the Arctic in November-December with values reaching about $-3^{\circ} \mathrm{C}$. A significant signal spreads down to midlatitudes from November to February, over North America and Europe. This result is consistent with other modeling studies (e.g., Peings and Magnusdottir 2014; Blackport and Kushner 2017; Collow et al. 2019) and with the study of Screen (2014), who found that Arctic amplification is coincident with a decrease in subseasonal temperature variability in middle and high latitudes, over the recent decades and under future climate forcing. It is also in agreement with the results of Schneider et al. (2015) based on an idealized general circulation model and CMIP5 models.

\section{Summary and discussion}

In this study we have investigated the rapid atmospheric response in autumn and winter to Arctic sea ice loss, using idealized experiments performed with the high-top climate model CNRM-CM6-1 in which sea ice albedo is reduced to the ocean value. With this protocol, an ice-free Arctic Ocean is obtained from July to October, leading to a very large Arctic amplification which is maximum in November. We first highlighted the physical mechanisms underlying the surface temperature response in the midlatitudes and the role of atmospheric circulation changes. To achieve this, we applied a dynamical adjustment method based on the regional reconstruction of circulation analogs and we decomposed the response into a dynamical and a residual contribution. We then focused our analysis on the circulation changes and discussed the possible interaction mechanisms between the tropospheric and stratospheric responses. Finally, we analyzed the impacts of Arctic sea ice loss on cold extreme temperatures in the midlatitudes. Hereinafter, we summarize the main findings of our study, and discuss their limitations and implications.

We found that surface temperature changes in response to Arctic sea ice decline reach the midlatitudes in autumn and winter, with a warming over Europe and North America from November to February and a cooling over central Asia from December to February. We showed that the warming over North America and Europe from November to February can be explained both by the circulation changes and by the advection of warmer air masses by the climatological flow originating from the Arctic or from other oceanic regions with increased SST. However, the cooling over central Asia from December to February is entirely explained by the dynamical changes occurring in response to the imposed Arctic sea ice reduction, involving an intensification of the Siberian high and a cyclonic response over the Sea of Okhotsk. The decomposition of the SAT response also allows to highlight that the month-to-month variations of the SAT response (e.g., the lack of cooling over central Asia in November unlike the other months, the lack of response over the western North America 

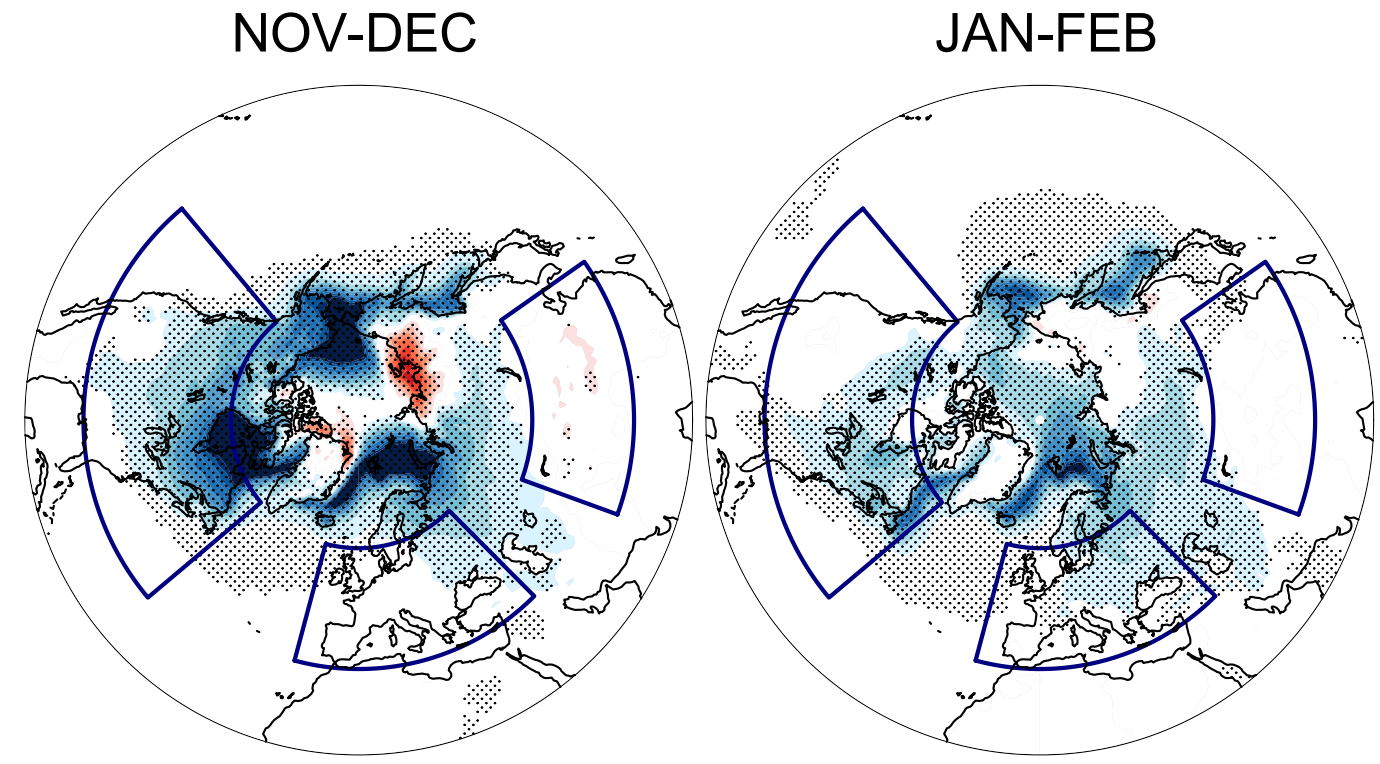

$(\operatorname{deg} \mathrm{C})$

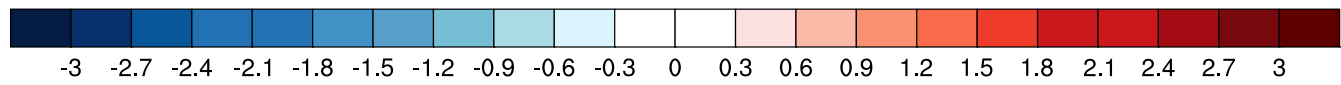

FIG. 13. Response of the standard deviation of the daily near-surface air temperature $\left({ }^{\circ} \mathrm{C}\right)$ for NovemberDecember and January-February. Dots indicate statistically significant grid points as described in Fig. 4.

in January, and over Europe in February) are mostly driven by the month-to-month variations in the dynamical component. Note that the sea level pressure changes used to compute the dynamical contribution are strongest in November-December (autumn), when Arctic amplification is strongest, with an intensification of the northeastern part of the Siberian high and the Aleutian low, a weakening of the Icelandic low, and a cyclonic anomaly over North America and the North Atlantic. These patterns are similar to the results of other coupled model studies reported in Screen et al. (2018), although investigating longer time scale responses, which supports the robustness of this response on various time scales. In January-February (winter) however, the sea level circulation response is weaker and more noisy due to lower signal-to-noise ratio. This can be interpreted both as a result of a larger atmospheric variability in winter than in autumn and also of a weaker sea ice forcing in winter than in autumn. Hence in our experiments, the dynamical contribution of the temperature response described in January-February is likely more influenced by internal variability than in November-December. The decomposition of the SAT response could also explain the differences that exist among some studies in the midlatitudes. In particular, the cooling over central Asia was suggested to be possibly weaker in ocean-atmosphere coupled experiments than in atmosphereonly experiments because of a greater offset by the residual warming effect (Screen et al. 2018; Deser et al. 2016a). In contrast, our results suggest that the cooling found over central Asia is entirely due to circulation changes and that there is no contribution of the residual warming.
Arctic sea ice loss also drives significant changes in atmospheric circulation up to the stratosphere and the tropics in our experiments. We find a narrowing of the subtropical jet stream and a southward shift of midlatitudes westerlies in November-December, which is in agreement with the results presented in Screen et al. (2018). The response is, again, weaker in January-February and is characterized by a slight southward shift of the zonal-mean zonal winds in February. In the stratosphere, we find that the response is characterized by a weakening of the lower part of the polar vortex in December, likely a result of the enhancement of upward planetary wave activity from the troposphere to the stratosphere. However, we hypothesize that this response is weak because of the weak constructive interference occurring between the forced and the climatological planetary waves. The following months, the atmospheric response is consistent with the negative phase of the NAM but the downward influence of the weak stratospheric anomalies probably plays a minor role on the tropospheric anomalies. Dedicated experiments in which the stratosphere is nudged toward a reference state like in Wu and Smith (2016) and Zhang et al. (2018) would be needed to isolate this link, which was beyond the scope of this study. A variety of polar vortex responses has been obtained among previous modeling studies, which could be explained by the different stratospheric mean states and highlights the importance of correctly representing the stratosphere in climate models. Labe et al. (2019) suggested that the phase of the QBO can modulate this response, with easterly (westerly) QBO favoring a weakening (strengthening) of the polar vortex. In our study, the QBO was initialized with a neutral phase, but 
additional composite analyses have revealed the same conclusion as the study of Labe et al. (2019). Further analysis and dedicated experiments are currently ongoing to better understanding the role of the QBO and other stratospheric processes in the atmospheric response to sea ice decline.

Finally, we have shown that in addition to affecting the midlatitude atmospheric mean state, Arctic sea ice loss in our experiments can also leads to less severe extreme cold temperatures over a great part of the midlatitudes and significantly decrease near-surface air temperature variability. More work has to be done in order to understand the physical processes at play in the extreme weather changes occurring in response to Arctic sea ice decline. Blackport and Screen (2020) showed that Arctic amplification and the resulting weakening of the midlatitude westerly winds does not necessarily imply a wavier circulation, in observations or models. They suggested instead that the causal relationship is opposite: changes in waviness are likely driving the changes in the meridional temperature gradient. Combined with internal variability, this could explain the absence or very weak waviness changes found in modeling studies so far in response to Arctic sea ice loss (e.g., Oudar et al. 2017). We have computed a waviness index over North America, Europe, and central Asia, based on Rossby wave packet envelope reconstruction pioneered by Zimin et al. (2003), and we found a very small decrease in the waviness of the jet stream in the three regions of interest. Further analysis is however needed to understand the link between waviness and temperature extreme changes in the CNRM-CM6.1 model, which will be done in future work.

The present study provides useful insights regarding the relative roles of dynamical and nondynamical processes in driving the impacts of Arctic sea ice loss on the midlatitude climate and weather. Higher-resolution experiments have been done as part of the H2020 PRIMAVERA project and the analysis of these simulations that will be documented in future work will allow us to determine whether the processes identified in this study are robust with changes in resolution.

Acknowledgments. This work has been funded by the European Union's Horizon 2020 programme under Grant Agreement 727862: APPLICATE (Advanced Prediction in Polar regions and beyond: Modelling, observing system design and LInkages associated with ArctiC ClimATE change). The designed experiments are part of the Horizon 2020 PRIMAVERA project (PRocess-based climate sIMulation: AdVances in high resolution modelling and European climate Risk Assessment, Grant Agreement 641727). We thank James Screen for valuable comments on this work and for hosting S. Chripko at the University of Exeter in April 2019. We also thank Christophe Cassou and Bruno Tremblay for helpful discussions, and the CNRM-CERFACS modelling group for developing the CNRM-CM6 model. We thank the three anonymous reviewers for their comments that helped to improve the manuscript.

Data availability statement. All the data used in this study are openly available and shared under request.

\section{REFERENCES}

Baldwin, M. P., and T. J. Dunkerton, 1999: Propagation of the Arctic Oscillation from the stratosphere to the troposphere. J. Geophys. Res., 104, 30 937-30 946, https://doi.org/10.1029/1999JD900445.

$\longrightarrow$, and — 2001: Stratospheric harbingers of anomalous weather regimes. Science, 294, 581-584, https://doi.org/10.1126/science. 1063315.

Barnes, E. A., 2013: Revisiting the evidence linking Arctic amplification to extreme weather in midlatitudes. Geophys. Res. Lett., 40, 4734-4739, https://doi.org/10.1002/grl.50880.

— the midlatitude jet-stream: Can it? Has it? Will it? Wiley Interdiscip. Rev.: Climate Change, 6, 277-286, https://doi.org/ 10.1002/wcc.337.

Bindoff, N., and Coauthors, 2013: Detection and attribution of climate change: From global to regional. Climate Change 2013: The Physical Science Basis. T. F. Stocker et al., Eds., Cambridge University Press, 867-952.

Bintanja, R., and E. van der Linden, 2013: The changing seasonal climate in the Arctic. Sci. Rep., 3, 1556, https://doi.org/10.1038/ srep01556.

Blackport, R., and P. J. Kushner, 2016: The transient and equilibrium climate response to rapid summertime sea ice loss in CCSM4. J. Climate, 29, 401-417, https://doi.org/10.1175/JCLID-15-0284.1.

— and — 2017: Isolating the atmospheric circulation response to Arctic sea ice loss in the coupled climate system. J. Climate, 30, 2163-2185, https://doi.org/10.1175/JCLI-D-16-0257.1.

_ autumn compared to that in winter on the atmospheric circulation. Geophys. Res. Lett., 46, 2213-2221, https://doi.org/ 10.1029/2018GL081469.

- , and - 2020: Insignificant effect of Arctic amplification on the amplitude of midlatitude atmospheric waves. Sci. Adv., 6 , eaay2880, https://doi.org/10.1126/sciadv.aay2880.

,-- K. van der Wiel, and R. Bintanja, 2019: Minimal influence of reduced Arctic sea ice on coincident cold winters in mid-latitudes. Nat. Climate Change, 9, 697-704, https://doi.org/ 10.1038/s41558-019-0551-4.

Butler, A. H., D. J. Seidel, S. C. Hardiman, N. Butchart, T. Birner, and A. Match, 2015: Defining sudden stratospheric warmings. Bull. Amer. Meteor. Soc., 96, 1913-1928, https://doi.org/ 10.1175/BAMS-D-13-00173.1.

Cassano, E. N., J. J. Cassano, M. E. Higgins, and M. C. Serreze, 2014: Atmospheric impacts of an Arctic sea ice minimum as seen in the Community Atmosphere Model. Int. J. Climatol., 34, 766-779, https://doi.org/10.1002/joc.3723.

Charlton, A. J., and L. M. Polvani, 2007: A new look at stratospheric sudden warmings. Part I: Climatology and modeling benchmarks. J. Climate, 20, 449-469, https://doi.org/10.1175/JCLI3996.1.

Charney, J. G., and P. G. Drazin, 1961: Propagation of planetaryscale disturbances from the lower into the upper atmosphere. J. Geophys. Res., 66, 83-109, https://doi.org/10.1029/ JZ066i001p00083.

Chen, H. W., F. Zhang, and R. B. Alley, 2016: The robustness of midlatitude weather pattern changes due to Arctic sea ice loss. J. Climate, 29, 7831-7849, https://doi.org/10.1175/JCLI-D-16-0167.1.

Cohen, J., J. C. Furtado, M. A. Barlow, V. A. Alexeev, and J. E. Cherry, 2012: Arctic warming, increasing snow cover and widespread boreal winter cooling. Environ. Res. Lett., 7, 014007, https://doi.org/10.1088/1748-9326/7/1/014007.

, J. Jones, J. C. Furtado, and E. Tziperman, 2013: Warm Arctic, cold continents: A common pattern related to Arctic sea ice melt, 
snow advance, and extreme winter weather. Oceanography, 26, 150-160, https://doi.org/10.5670/oceanog.2013.70.

— , and Coauthors, 2014: Recent Arctic amplification and extreme mid-latitude weather. Nat. Geosci., 7, 627-637, https:// doi.org/10.1038/ngeo2234.

— , and Coauthors, 2020: Divergent consensuses on Arctic amplification influence on midlatitude severe winter weather. Nat. Climate Change, 10, 20-29, https://doi.org/10.1038/s41558-019-0662-y.

Collow, T. W., W. Wang, and A. Kumar, 2019: Reduction in northern midlatitude $2-\mathrm{m}$ temperature variability due to Arctic sea ice loss. J. Climate, 32, 5021-5035, https://doi.org/ 10.1175/JCLI-D-18-0692.1.

Craig, A., S. Valcke, and L. Coquart, 2017: Development and performance of a new version of the OASIS coupler, OASIS3MCT_3. 0. Geosci. Model Dev., 10, 3297-3308, https://doi.org/ 10.5194/gmd-10-3297-2017.

Dai, A., and M. Song, 2020: Little influence of Arctic amplification on mid-latitude climate. Nat. Climate Change, 10, 231-237, https://doi.org/10.1038/s41558-020-0694-3.

Deser, C., R. A. Tomas, M. Alexander, and D. Lawrence, 2010: The seasonal atmospheric response to projected Arctic sea ice loss in the late twenty-first century. J. Climate, 23, 333-351, https://doi.org/10.1175/2009JCLI3053.1.

,-- , and L. Sun, 2015: The role of ocean-atmosphere coupling in the zonal-mean atmospheric response to Arctic sea ice loss. J. Climate, 28, 2168-2186, https://doi.org/10.1175/JCLID-14-00325.1.

_ L. Lun, R. A. Tomas, and J. Screen, 2016a: Does ocean coupling matter for the northern extratropical response to projected Arctic sea ice loss? Geophys. Res. Lett., 43, 21492157, https://doi.org/10.1002/2016GL067792.

- L. Terray, and A. S. Phillips, 2016b: Forced and internal components of winter air temperature trends over North America during the past 50 years: Mechanisms and implications. J. Climate, 29, 2237-2258, https://doi.org/10.1175/JCLID-15-0304.1.

Edmon, H., Jr., B. Hoskins, and M. McIntyre, 1980: EliassenPalm cross sections for the troposphere. J. Atmos. Sci., 37, 2600-2616, https://doi.org/10.1175/1520-0469(1980)037<2600: EPCSFT $>2.0 . \mathrm{CO} ; 2$.

England, M. R., L. M. Polvani, L. Sun, and C. Deser, 2020: Tropical climate responses to projected Arctic and Antarctic sea-ice loss. Nat. Geosci., 13, 275-281, https://doi.org/10.1038/s41561020-0546-9.

Francis, J. A., and S. J. Vavrus, 2012: Evidence linking Arctic amplification to extreme weather in mid-latitudes. Geophys. Res. Lett., 39, L06801, https://doi.org/10.1029/2012GL051000.

García-Serrano, J., C. Frankignoul, G. Gastineau, and A. de la Cámara, 2015: On the predictability of the winter Euro-Atlantic climate: Lagged influence of autumn Arctic sea ice. J. Climate, 28, 5195-5216, https://doi.org/10.1175/JCLI-D-14-00472.1.

Garfinkel, C. I., D. L. Hartmann, and F. Sassi, 2010: Tropospheric precursors of anomalous Northern Hemisphere stratospheric polar vortices. J. Climate, 23, 3282-3299, https://doi.org/ 10.1175/2010JCLI3010.1.

Good, S. A., M. J. Martin, and N. A. Rayner, 2013: EN4: Quality controlled ocean temperature and salinity profiles and monthly objective analyses with uncertainty estimates. J. Geophys. Res. Oceans, 118, 6704-6716, https://doi.org/10.1002/2013JC009067.

Haarsma, R. J., and Coauthors, 2016: High Resolution Model Intercomparison Project (HighResMIP v1.0) for CMIP6. Geosci. Model Dev., 9, 4185-4208, https://doi.org/10.5194/ gmd-9-4185-2016.
Holton, J. R., 1992: An introduction to Dynamic Meteorology. 3rd ed. Academic Press, 511 pp.

Jaiser, R., K. Dethloff, D. Handorf, A. Rinke, and J. Cohen, 2012: Impact of sea ice cover changes on the Northern Hemisphere atmospheric winter circulation. Tellus, 64A, 11595, https:// doi.org/10.3402/tellusa.v64i0.11595.

,-- , and 2013: Stratospheric response to Arctic sea ice retreat and associated planetary wave propagation changes. Tellus, 65A, 19375, https://doi.org/10.3402/tellusa.v65i0. 19375.

Kim, B.-M., S.-W. Son, S.-K. Min, J.-H. Jeong, S.-J. Kim, X. Zhang, T. Shim, and J.-H. Yoon, 2014: Weakening of the stratospheric polar vortex by Arctic sea-ice loss. Nat. Commun., 5, 4646, https://doi.org/10.1038/ncomms5646.

Labe, Z., Y. Peings, and G. Magnusdottir, 2019: The effect of QBO phase on the atmospheric response to projected Arctic sea-ice loss in early winter. Geophys. Res. Lett., 46, 7663-7671, https:// doi.org/10.1029/2019GL083095.

Limpasuvan, V., D. W. Thompson, and D. L. Hartmann, 2004: The life cycle of the Northern Hemisphere sudden stratospheric warmings. J. Climate, 17, 2584-2596, https://doi.org/10.1175/ 1520-0442(2004)017<2584:TLCOTN $>2.0$.CO;2.

Madec, G., and Coauthors, 2017: Nemo ocean engine. Note du Pôle de modélisation de l'Institut Pierre-Simon-Laplace, No. 27, 412 pp., https://doi.org/10.5281/zenodo.3248739.

Magnusdottir, G., C. Deser, and R. Saravanan, 2004: The effects of North Atlantic SST and sea ice anomalies on the winter circulation in CCM3. Part I: Main features and storm track characteristics of the response. J. Climate, 17, 857-876, https://doi.org/ 10.1175/1520-0442(2004)017<0857:TEONAS > 2.0.CO;2.

McCusker, K. E., J. C. Fyfe, and M. Sigmond, 2016: Twenty-five winters of unexpected Eurasian cooling unlikely due to Arctic sea-ice loss. Nat. Geosci., 9, 838-842, https://doi.org/10.1038/ngeo2820.

McKenna, C. M., T. J. Bracegirdle, E. F. Shuckburgh, P. H. Haynes, and M. M. Joshi, 2018: Arctic sea ice loss in different regions leads to contrasting Northern Hemisphere impacts. Geophys. Res. Lett., 45, 945-954, https://doi.org/10.1002/2017GL076433.

Meleshko, V. P., O. M. Johannessen, A. V. Baidin, T. V. Pavlova, and V. A. Govorkova, 2016: Arctic amplification: Does it impact the polar jet stream? Tellus, 68A, 32330, https:// doi.org/10.3402/tellusa.v68.32330.

Meredith, M., and Coauthors, 2019: Polar regions. IPCC Special Report on the Ocean and Cryosphere in a Changing Climate, H.-O. Pörtner et al., Eds., IPCC, https://www.ipcc.ch/srocc.

Mori, M., M. Watanabe, H. Shiogama, J. Inoue, and M. Kimoto, 2014: Robust Arctic sea-ice influence on the frequent Eurasian cold winters in past decades. Nat. Geosci., 7, 869-873, https:// doi.org/10.1038/ngeo2277.

_- Y. Kosaka, M. Watanabe, H. Nakamura, and M. Kimoto, 2019: A reconciled estimate of the influence of Arctic sea-ice loss on recent Eurasian cooling. Nat. Climate Change, 9, 123129, https://doi.org/10.1038/s41558-018-0379-3.

Nakamura, T., K. Yamazaki, K. Iwamoto, M. Honda, Y. Miyoshi, Y. Ogawa, and J. Ukita, 2015: A negative phase shift of the winter AO/NAO due to the recent Arctic sea-ice reduction in late autumn. J. Geophys. Res., 120, 3209-3227, https://doi.org/ 10.1002/2014JD022848.

2016: The stratospheric pathway for Arctic impacts on midlatitude climate. Geophys. Res. Lett., 43, 3494-3501, https:// doi.org/10.1002/2016GL068330.

Notz, D., and Coauthors, 2020: Arctic sea ice in CMIP6. Geophys. Res. Lett., 47, e2019GL086749, https://doi.org/10.1029/2019GL086749. 
Ogawa, F., and Coauthors, 2018: Evaluating impacts of recent Arctic sea ice loss on the Northern Hemisphere winter climate change. Geophys. Res. Lett., 45, 3255-3263, https://doi.org/ 10.1002/2017GL076502.

Onarheim, I. H., T. Eldevik, L. H. Smedsrud, and J. C. Stroeve, 2018: Seasonal and regional manifestation of Arctic sea ice loss. J. Climate, 31, 4917-4932, https://doi.org/10.1175/JCLID-17-0427.1.

O'Reilly, C. H., T. Woollings, and L. Zanna, 2017: The dynamical influence of the Atlantic multidecadal oscillation on continental climate. J. Climate, 30, 7213-7230, https://doi.org/ 10.1175/JCLI-D-16-0345.1.

Osborne, J. M., J. A. Screen, and M. Collins, 2017: Oceanatmosphere state dependence of the atmospheric response to Arctic sea ice loss. J. Climate, 30, 1537-1552, https://doi.org/ 10.1175/JCLI-D-16-0531.1.

Oudar, T., E. Sanchez-Gomez, F. Chauvin, J. Cattiaux, L. Terray, and C. Cassou, 2017: Respective roles of direct GHG radiative forcing and induced Arctic sea ice loss on the Northern Hemisphere atmospheric circulation. Climate Dyn., 49, 36933713, https://doi.org/10.1007/s00382-017-3541-0.

Overland, J. E., K. R. Wood, and M. Wang, 2011: Warm Arctic-cold continents: Climate impacts of the newly open Arctic sea. Polar Res., 30, 15 787, https://doi.org/10.3402/polar.v30i0.15787.

Peings, Y., and G. Magnusdottir, 2014: Response of the wintertime Northern Hemisphere atmospheric circulation to current and projected Arctic sea ice decline: A numerical study with CAM5. J. Climate, 27, 244-264, https://doi.org/10.1175/JCLID-13-00272.1.

- Z Z. M. Labe, and G. Magnusdottir, 2021: Are 100 ensemble members enough to capture the remote atmospheric response to $+2^{\circ} \mathrm{C}$ Arctic sea ice loss? J. Climate, 34, 3751-3769, https:// doi.org/10.1175/JCLI-D-20-0613.1.

Rao, J., C. I. Garfinkel, and I. P. White, 2020: Impact of the quasibiennial oscillation on the northern winter stratospheric polar vortex in CMIP5/6 models. J. Climate, 33, 4787-4813, https:// doi.org/10.1175/JCLI-D-19-0663.1.

Ronalds, B., E. A. Barnes, R. Eade, Y. Peings, and M. Sigmond, 2020: North Pacific zonal wind response to sea ice loss in the Polar Amplification Model Intercomparison Project and its downstream implications. Climate Dyn., 55, 1779-1792, https:// doi.org/10.1007/s00382-020-05352-w.

Schneider, T., T. Bischoff, and H. Płotka, 2015: Physics of changes in synoptic midlatitude temperature variability. J. Climate, 28, 2312-2331, https://doi.org/10.1175/JCLI-D14-00632.1.

Schweiger, A., R. Lindsay, J. Zhang, M. Steele, H. Stern, and R. Kwok, 2011: Uncertainty in modeled Arctic sea ice volume. J. Geophys. Res. Oceans, 116, C00D06, https://doi.org/10.1029/ 2011JC007084.

Screen, J. A., 2014: Arctic amplification decreases temperature variance in northern mid- to high-latitudes. Nat. Climate Change, 4 (7), 577-582, https://doi.org/10.1038/nclimate2268.

_ 2017 : The missing northern European winter cooling response to Arctic sea ice loss. Nat. Commun., 8, 14 603, https:// doi.org/10.1038/ncomms14603.

— ice in recent Arctic temperature amplification. Nature, 464, 1334-1337, https://doi.org/10.1038/nature09051.

— , and - 2010b: Increasing fall-winter energy loss from the Arctic Ocean and its role in Arctic temperature amplification. Geophys. Res. Lett., 37, L16707, https://doi.org/10.1029/ 2010 GL044136.
,-- C. Deser, and R. Tomas, 2013: The atmospheric response to three decades of observed Arctic sea ice loss. J. Climate, 26, 1230-1248, https://doi.org/10.1175/JCLI-D-12-00063.1.

- - C. Deser, I. Simmonds, and R. Tomas, 2014: Atmospheric impacts of Arctic sea-ice loss, 19792009: Separating forced change from atmospheric internal variability. Climate Dyn., 43, 333-344, https:// doi.org/10.1007/s00382-013-1830-9.

,-- , and L. Sun, 2015: Reduced risk of North American cold extremes due to continued Arctic sea ice loss. Bull. Amer. Meteor. Soc., 96, 1489-1503, https://doi.org/10.1175/BAMS-D14-00185.1.

— , and Coauthors, 2018: Consistency and discrepancy in the atmospheric response to Arctic sea-ice loss across climate models. Nat. Geosci., 11, 155-163, https://doi.org/10.1038/ s41561-018-0059-y.

Semmler, T., L. Stulic, T. Jung, N. Tilinina, C. Campos, S. Gulev, and D. Koracin, 2016: Seasonal atmospheric responses to reduced Arctic sea ice in an ensemble of coupled model simulations. J. Climate, 29, 5893-5913, https://doi.org/10.1175/JCLI-D-15-0586.1.

Serreze, M., A. Barrett, J. Stroeve, D. Kindig, and M. Holland, 2009: The emergence of surface-based Arctic amplification. Cryosphere, 3, 11-19, https://doi.org/10.5194/tc-3-11-2009.

Shaw, T. A., J. Perlwitz, and O. Weiner, 2014: Tropospherestratosphere coupling: Links to North Atlantic weather and climate, including their representation in CMIP5 models. J. Geophys. Res., 119, 5864-5880, https://doi.org/10.1002/ 2013JD021191.

Smith, D. M., N. J. Dunstone, A. A. Scaife, E. K. Fiedler, D. Copsey, and S. C. Hardiman, 2017: Atmospheric response to Arctic and Antarctic sea ice: The importance of ocean-atmosphere coupling and the background state. J. Climate, 30, 4547-4565, https:// doi.org/10.1175/JCLI-D-16-0564.1.

Smith, K. L., and P. J. Kushner, 2012: Linear interference and the initiation of extratropical stratosphere-troposphere interactions. J. Geophys. Res., 117, D13107, https://doi.org/10.1029/ 2012JD017587.

Stroeve, J. C., M. C. Serreze, M. M. Holland, J. E. Kay, J. Malanik, and A. P. Barrett, 2012: The Arctic's rapidly shrinking sea ice cover: A research synthesis. Climatic Change, 110, 1005-1027, https://doi.org/10.1007/s10584-011-0101-1.

Sun, L., C. Deser, L. Polvani, and R. Tomas, 2014: Influence of projected Arctic sea ice loss on polar stratospheric ozone and circulation in spring. Environ. Res. Lett., 9, 084016, https:// doi.org/10.1088/1748-9326/9/8/084016.

,$- \ldots$, and R. A. Tomas, 2015: Mechanisms of stratospheric and tropospheric circulation response to projected Arctic sea ice loss. J. Climate, 28, 7824-7845, https://doi.org/10.1175/ JCLI-D-15-0169.1.

—, J. Perlwitz, and M. Hoerling, 2016: What caused the recent "warm Arctic, cold continents" trend pattern in winter temperatures? Geophys. Res. Lett., 43, 5345-5352, https://doi.org/ 10.1002/2016GL069024.

- M. Alexander, and C. Deser, 2018: Evolution of the global coupled climate response to Arctic sea ice loss during 19902090 and its contribution to climate change. J. Climate, 31, 7823-7843, https://doi.org/10.1175/JCLI-D-18-0134.1.

Teweles, S., Jr., and H. B. Wobus, 1954: Verification of prognostic charts. Bull. Amer. Meteor. Soc., 35, 455-463, https://doi.org/ 10.1175/1520-0477-35.10.455.

Vihma, T., 2014: Effects of Arctic sea ice decline on weather and climate: A review. Surv. Geophys., 35, 1175-1214, https:// doi.org/10.1007/s10712-014-9284-0. 
Voldoire, A., and Coauthors, 2019: Evaluation of CMIP6 DECK experiments with CNRM-CM6-1. J. Adv. Model. Earth Syst., 11, 2177-2213, https://doi.org/10.1029/2019MS001683.

Wang, K., C. Deser, L. Sun, and R. A. Tomas, 2018: Fast response of the tropics to an abrupt loss of Arctic sea ice via ocean dynamics. Geophys. Res. Lett., 45, 4264-4272, https://doi.org/ 10.1029/2018GL077325.

Wilks, D., 2016: “The stippling shows statistically significant grid points": How research results are routinely overstated and overinterpreted, and what to do about it. Bull. Amer. Meteor. Soc., 97, 2263-2273, https://doi.org/10.1175/BAMSD-15-00267.1.
Wu, Y., and K. L. Smith, 2016: Response of Northern Hemisphere midlatitude circulation to Arctic amplification in a simple atmospheric general circulation model. J. Climate, 29, 20412058, https://doi.org/10.1175/JCLI-D-15-0602.1.

Zhang, P., Y. Wu, I. R. Simpson, K. L. Smith, X. Zhang, B. De, and P. Callaghan, 2018: A stratospheric pathway linking a colder Siberia to Barents-Kara Sea sea ice loss. Sci. Adv., 4, eaat6025, https://doi.org/10.1126/sciadv.aat6025.

Zimin, A. V., I. Szunyogh, D. Patil, B. R. Hunt, and E. Ott, 2003: Extracting envelopes of Rossby wave packets. Mon. Wea. Rev., 131, 1011-1017, https://doi.org/10.1175/1520-0493(2003) 131<1011:EEORWP>2.0.CO;2. 